\title{
Urban Growth, Transport Planning, Air Quality and Health: A Multi-Objective Spatial Analysis Framework for a Linear Monocentric City
}

\author{
Judith Y. T. Wang1 • Richard D. Connors ${ }^{2}$
}

Published online: 30 May 2018

(C) The Author(s) 2018

\begin{abstract}
In this paper, we propose a multi-objective spatial analysis framework to evaluate the economic, environmental and health impacts of transport investment strategies under different urban growth scenarios. We consider a linear monocentric city (LMC) wherein residents are distributed continuously along an urban corridor and commute daily to a common destination, the central business district (CBD), represented by one end of the linear city. Two modes are available: car and rail. Users can travel from their residence to the CBD by car on a congestible highway with stochastic travel time, or by rail from the most convenient nearby station, which they reach by walking or cycling. Travellers throughout the city have a distribution of reliability preferences. Individual mode choice is determined using the notion of travel time budget surplus to take into consideration the travel time, travel time reliability and monetary cost associated with each mode. We assume users would like to minimise travel time, monetary cost, and maximise travel time reliability. The resulting formulation is a three-objective user equilibrium model (TBSmaxTUE). For the continuous monocentric city model, TBSmaxTUE can be formulated as a fixed point problem. To admit a numerical solution the continuum is discretised, allowing it to be expressed as a standard network equilibrium assignment problem. The performance of this LMC model can then be analysed against multiple objectives. We consider the economic objective to minimise total system travel time; the environmental objective
\end{abstract}

Judith Y. T. Wang

j.y.t.wang@leeds.ac.uk

Richard D. Connors

r.d.connors@leeds.ac.uk

1 School of Civil Engineering and Institute for Transport Studies, University of Leeds, Leeds, UK

2 Institute for Transport Studies, University of Leeds, Leeds, UK 
to minimise total tailpipe emissions from car trips; and health objectives to minimise pollutant uptake while also maximising the level of physical activity during the journey to work.

Keywords Network equilibrium · Multi-objective user equilibrium · Mode choice · Linear monocentric city $\cdot$ Air quality $\cdot$ Health impact

\section{Introduction}

Urban sprawl is observed in many countries around the world after decades of road dominated infrastructure investment. The evolution of urban form is, to a certain extent, the result of people's choices regarding where to live, where to work and how to travel. The assumption of rational behaviour presupposes that people make choices according to their preferences. That is, some of those who live in rural suburbs might have chosen to live there because there are certain qualities they enjoy in these areas, while others might be living there because they cannot afford to live near the city centre. Urban sprawl leads to a vicious circle of low-density development in rural areas and car dependency, which is unsustainable. High density mixed development has been considered as one of the strategies to moderate this problem, yet this might not be universally preferred. Promoting smart, green and integrated transport is considered a priority in the strategic move towards sustainable development by the European Union and many other countries worldwide. This is reflected by the numerous studies on designing, modelling and promoting green transport/bikesharing systems (e.g. Bao et al. (2017), Kitthamkesorn et al. (2016), and Lin and Liao (2016)); and environmental constraints/efficiency as well as sustainability have been considered explicitly in many transport network design studies (e.g. Li et al. (2014, 2016), Maheshwari et al. (2016), Yang et al. (2017)).

There is no doubt that to plan for sustainable cities, we must consider the effect of transport policy on the environment in terms of air quality and its subsequent effect on health. As suggested by Engardt et al. (2011), there are various factors influencing air quality within a planning horizon of 20 to 30 years: the global effect of climate change as well as local effects of urban form need to be considered. At the local level, the design of transportation systems and transport policies will influence the city's own contribution to air pollution. The travel choices made by inhabitants not only determine their contribution to urban emissions, but also influence their own health, which in turn determines the health sustainability of society as a whole. Empirical evidence from the last decade has shown that the characteristics of city and regional land use and transport planning are directly linked with air quality, individual exposure, uptake of pollutants and subsequent health outcomes (e.g. de Nazelle et al. (2011), Schindler and Caruso (2014), and Sider et al. (2013)). de Nazelle et al. also demonstrated that assessing the health impact of active travel policies needs to account for the connections between transport policies, planning and health. In particular, numerous studies have looked at the potential health benefits of cycling, as reviewed in Mueller et al. (2015) and Oja et al. (2011). As part of daily life, cycling can indeed improve public health, with the dominant benefits arising from increased 
physical activity during travel, in particular by replacing short car trips of $5-7 \mathrm{~km}$ with bicycle trips (Götschi et al. 2016; Mueller et al. 2015).

To quantify the health impacts from transport related physical activity as well as changes to air pollution, Woodcock et al. (2013) applied an Integrated Transport and Health Impact Modelling Tool (ITHIM), developed from the work in Woodcock et al. (2009). However, a key assumption in ITHIM is that the reduction in road transport trips, as a result of increases in walking and cycling instead of car use, led to equal proportional reduction in pollutants attributed to transport. That is, the effect of changes in traffic congestion on air pollution was not modelled. This might lead to overestimation or underestimation of the potential benefits of change in air quality to cyclists. As cyclists exercise their breathing rate increases, so that they might breathe in more pollutants than car drivers, as shown by experimental results in Auckland (Dirks et al. 2012) and Barcelona (de Nazelle et al. 2012). Cycling might therefore not always bring desired health benefits, depending on the concentrations of pollutants the cyclists encounter and the travel time they spend. Although the impact of air pollution might appear small when compared to the benefits of increased physical activity in previous studies (Götschi et al. 2016; Mueller et al. 2015), this may not be the case when local differences in air quality due to spatially non-uniform traffic congestion are considered. The health impact of an increase in cycling trips to suburban rail stations will be different from a similar increase in cycling trips to the city centre. Thus, both the benefits of physical activity and pollutant uptake during the journey should be considered when evaluating the health consequences of transport mode choice. Schepers et al. (2015) assess the potential health impact of investment in cycling infrastructure in a hypothetical city considering both the influence of changes in physical activity and pollutant uptake. However, the assessment is based on exogenously imposed changes to mean concentrations. The effect of travel behavioural change in terms of modal shift from driving to cycling is not modelled.

There is also a rich literature linking strategic transport planning models with air quality models, e.g. Affum et al. (2003), Boogaard et al. (2012), Hatzopoulou and Miller (2010), Lee et al. (2009), and You et al. (2010). The general approach taken by most integrated transport planning and air quality models is to take traffic information from the transport planning model, including traffic flow, speed and vehicle types on each roadway. These are input into an air quality model. Vehicle emission and dispersion models are applied to deduce concentrations of pollutants and hence population exposure can also be assessed (Hatzopoulou and Miller 2010; Shekarrizfard et al. 2015; Sider et al. 2013), where air pollution exposure is measured by a proxy variable, i.e. the level of emissions occurring in a zone. Mode-specific exposure and pollutant uptake during travel, accounting for activity level, which is an important element in health impact assessment as explained above, have not been explicitly included in such models.

Public transport investment can attract modal shift from car trips, and potentially can have positive effects on population health. In addition to the health benefits from increased physical activity during access and egress at the trip ends, users of non-road based public transport, such as rail, might acquire additional benefits from less pollutant uptake during travel due to reduced exposure in a better air quality 
environment (Dirks et al. 2012). Most of the work on health impact assessment has been focussed on the benefits of cycling more than any other modes that involves an active component. In Mueller et al.'s review, out of 30 selected papers, the benefits from changes in public transport policy have been explicitly mentioned in only six cases (Mueller et al. 2015, Table 1). The potential health benefits of modal shifts from car trips to public transport such as rail is worth further exploration.

In summary, despite a rich literature linking transport modelling to air quality as well as health impact assessment of modal shifts from car to cycling, there are a few knowledge gaps in the existing methodology:

1. the health impact should include both physical activity benefits and pollutant uptake;

2. the localised effect on spatial pattern of air quality as a result of transport choices (e.g. mode choice, route choice, etc.) of residents should be considered; and

3. the exposure encountered by travellers on different modes at different locations throughout their trip should be estimated based on their physical activity on different modes as well as the spatial pattern of air quality concentrations.

In an ideal world, we would hope that everyone can enjoy living in a suburb or in the city as they desire; be able to get to work within reasonable time and cost on a comfortable mode of transport; live and work in a nice clean environment; and most important of all, stay healthy. From a modelling point of view, an ideal planning model should be able to support the analysis of the effectiveness of policy decisions in terms of all of these aspects, i.e. economic, environmental and health impact, taking into consideration users' behavioural response and its subsequent effect on the environmental and public health. In particular, the health impact assessment should cover the knowledge gaps identified above.

In the present paper, we will look at one particular missing element at the policy level: the inclusion of potential health benefits of transport investment decisions, in particular active mobility (walking or cycling), which most often occurs as the means to access public transport facilities. Our methodology is developed for the assessment in a multi-modal environmental, i.e. we assess the potential health impact of active modes both as a means to replace car trips and as an access/egress mode for multimodal trips with public transport. This requires a multi-objective approach as found in many studies in the literature. For example Lin and Liao (2016) considered sustainability with multiple objectives in a bikeway network design problem; Lin et al. (2016) incorporated the cost of environmental constraints in a bi-level programming framework to assess the interaction of traffic with its environmental impacts; and Miandoabchi et al. (2012) looked at a bi-modal multi-objective urban road and public transit network problem. Here, in particular, we model decisions with multiple objectives at two levels: (1) urban growth, transport planning, air quality and health impact assessment at the policy decision level; and (2) behavioural response at the user level in terms of mode and route choice. A typical decision analysis framework (with multiple objectives considered at both the government and users' levels) is illustrated in Fig. 1.

As highlighted earlier, an important knowledge gap in the literature is the modelling of air quality at different locations arising from travel choices and the 


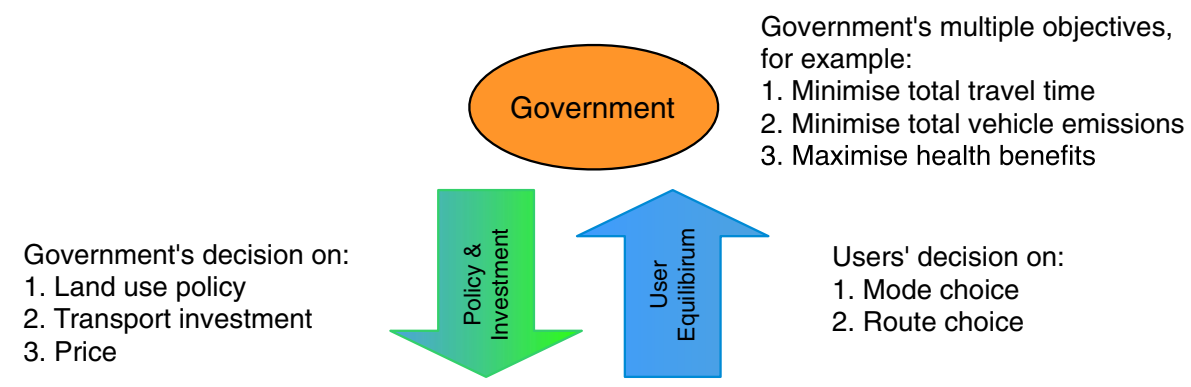

Equilibrium Analysis

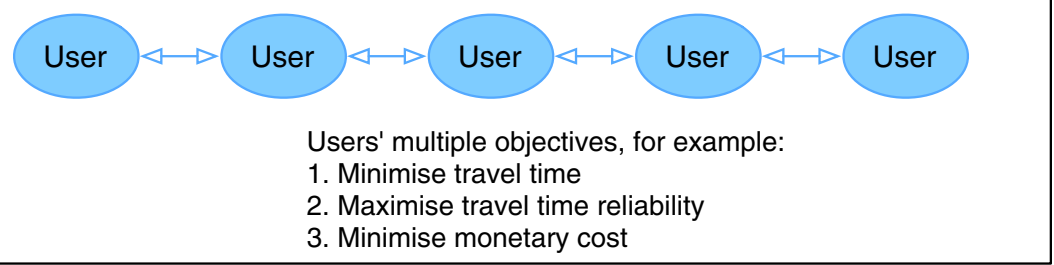

Fig. 1 A typical decision analysis framework with multiple objectives

subsequent effect on pollutant uptake of individuals using different (multiple) modes during their journey. We, therefore, focus on two new aspects within this analysis framework:

1. Policy level: the modelling of health benefits with multiple objectives, namely, physical activity and pollutant uptake.

2. User level: the modelling of users' mode choice behaviour considering three objectives, namely, travel time, travel time reliability and monetary cost.

From an optimisation point of view, this suggests a bi-level network design problem (NDP), with a classical general formulation in Ben-Ayed et al. (1988). Typically NDPs have single objectives at both the lower and upper levels. More recently, multiple objectives have been considered at the upper level (e.g. Miandoabchi et al. (2012) and Szeto et al. (2015)). Meanwhile, multiple objectives have not been considered at the lower (user equilibrium) level in the context of a bi-level NDP. Multi-objective equilibrium models have been introduced in recent research with a view to more realistic modelling of route choice behaviour (Ehrgott et al. 2015; Wang and Ehrgott 2013; Wang et al. 2014a).

In this study, we introduce a multi-objective equilibrium model at the lower level for a bi-modal network in order to determine more realistically where modal shifts might occur and where active modes are used. With this formulation at the lower level, multiple system performance indicators can be observed at the upper level for different (pre-defined) urban growth and transport investment scenarios. In particular, the lower level model enables a health impact assessment (at the upper level) that takes into the spatially disaggregate emissions concentrations encountered by travellers, and mode-specific uptake of pollutants. This provides the necessary foundation for multi-objective optimisation at the upper level (subject to multi-objective 
equilibrium at the lower level). The multi-objective bi-level NDP (with multiple objectives considered at both levels) will be a subject for future research.

To support the strategic analysis of different urban growth scenarios and transport investment strategies, we need not only a representation of the transport infrastructure but also a model of the city, where the urban form and environment in terms of air quality can be modelled. We adopt a classical urban model, known as the linear monocentric city.

As shown in Fielbaum et al. (2017), there are many different ways to represent the urban form of a city. The monocentric city is one such abstract form, which originated from models developed in the 1960s (e.g. Alonso $(1960,1964))$ to support urban density analysis. In its simplest form, the city is represented as a disc with radial distance from the central CBD the key explanatory variable. Smith's review suggests that 'a monocentric population density model can be viewed as a one-origin, manydestination version of a spatial interaction model' (cited in Smith (1997) from Wilson (1970)). For the morning commute, this becomes a many-origin, one-destination spatial interaction model. With improved data availability and computational efficiency in the 70s and 80s, the use of monocentric mathematical urban density models has become a popular approach (e.g. Anas (1990) and Mohan (1979)). Until today, this classical urban density model is still a building block for many urban economics models. For instance, a recent article has shown that a monocentric model can be extended to model the effect of congestion pricing in the Paris region (with multiple centres) and its long term change in urban form (De Lara et al. 2013).

The linear monocentric city model (LMC) may be thought of as collapsing the circular symmetry of the monocentric city into one representative radial corridor. However, in the first thorough mathematical treatment of the LMC it was simply introduced as 'a traffic corridor problem with several congested modes, a continuum of entry points and a single exit point' by Jehiel (1993), in a paper that provided formulations for both user equilibrium and system optimum, along with results on the existence and uniqueness of solutions. Over the years, the modelling of spatial interactions of transport policy, the transport system and the urban form within a linear monocentric city has also been well studied. Some examples include the optimisation problems of location and pricing of Parkand-Ride facilities (e.g. Liu et al. (2009) and Wang et al. (2004)); congestion pricing (e.g. Chen et al. (2017), Li et al. (2014), and Liu et al. (2014)); and public transport investment strategies (e.g. Li et al. (2012a, b)). All of these studies have focussed on the economic and/or welfare aspects. The present study is the first to look at the interactions with the environment and the subsequent health impact of transport investment within a linear monocentric city modelling framework.

We propose a multi-objective spatial analysis framework to evaluate the economic, environmental and health impacts of transport investment strategies under different urban growth scenarios. We consider a linear monocentric city wherein residents are distributed continuously along an urban corridor and commute daily to a common destination, the central business district (CBD), represented by one end of the linear city. Two modes are available: car and rail. Users either travel by car from their residence to the $\mathrm{CBD}$, or by rail from the nearest station, which they reach by walking 
or cycling. There is also the alternative to walk/cycle directly to the $\mathrm{CBD}$, without using train or car.

As in many previous studies, we need to consider co-evolution of urban growth and its interactions with choices made by residents (e.g. Li et al. (2016) and Maheshwari et al. (2016)) as well as the influence of different transport investment strategies on the behaviour of residents (e.g. Stepniak and Rosik (2017)). We illustrate the model with two cases of urban growth (Huang et al. 2014): (1) horizontal growth (length of the city) to represent urban sprawl; and (2) vertical growth (population density) to represent higher density development. In both scenarios we assume that the co-evolution of residential land use and road infrastructure follows scaling law growth (Bettencourt et al. 2007) and that, for simplicity, population density is uniform. The model presented can, without modification, accommodate any (exogenously defined) population distribution, however residential location choice is not modelled within this equilibrium framework.

We adopt a multi-objective approach (Wang and Ehrgott 2013; Wang et al. 2014a) to model individual mode choice decisions taking into consideration travel time, travel time reliability and monetary cost associated with each mode. It is important to include travel time reliability when considering commuter mode choice since empirical evidence reveals rail as an attractive alternative to driving, not only for short commute within the urban area but also for long distance commuting (Wang 2011); travel time reliability and travel comfort are the two most important dimensions of the journey that affects the overall satisfaction (Brons and Rietveld 2009).

We consider multiple system performance parameters at the policy level, in terms of aggregate information on vehicle emissions as well as disaggregate information on both individual pollutant uptake and exercise level during journey to work. The availability of individual activity information enables health impact analyses to be carried out both spatially and temporally at an appropriate level of detail that can support informed policy decisions.

This paper contributes a configurable multi-modal model, including active modes, that represents the multi-objective trade-offs faced by travellers in terms of travel time, travel cost and travel time reliability. The model is sufficiently spatially disaggregate to capture health impacts due to activity-related uptake of localised emissions arising from road traffic congestion. The model is used to explore alternative urban growth scenarios via multiple system performance indicators, revealing the upperlevel trade-offs faced by policy makers and demonstrating the potential of this modelling framework for future application to a multi-objective bi-level NDP (with multiple objectives considered at both levels).

This paper is organised as follows. The next section introduces the modelling suite, including an overview of the four modelling components: the urban growth, transport planning, air quality modelling and health impact assessment components. The mathematical formulation of the model is then described in Section 3. We then demonstrate with numerical examples in Section 4 how this modelling suite can be applied to support policy analysis. Finally, conclusions are drawn in Section 5 followed by a discussion on further research topics. 


\section{Model Overview}

An overview of the modelling suite is depicted in Fig. 2, consisting of two sets of sub-components: (a) the urban growth and transport planning components; and (b) the air quality and health impact assessment components.

\subsection{The Urban Growth and Transport Planning Components}

As shown in Fig. 2a, the urban growth and transport planning components include two processes: (i) system specification; and (ii) equilibrium analysis.

\subsubsection{System Specification}

The idea behind this linear monocentric city model with continuum demand distribution is to represent a general planning/design problem that urban/transport planners face every day. Let us consider any typical congested corridor in a city, where there exists only one road connection at the moment and with population growth, the corridor has now become congested. We consider two possible transport infrastructure investment strategies here: (1) increase road capacity to satisfy

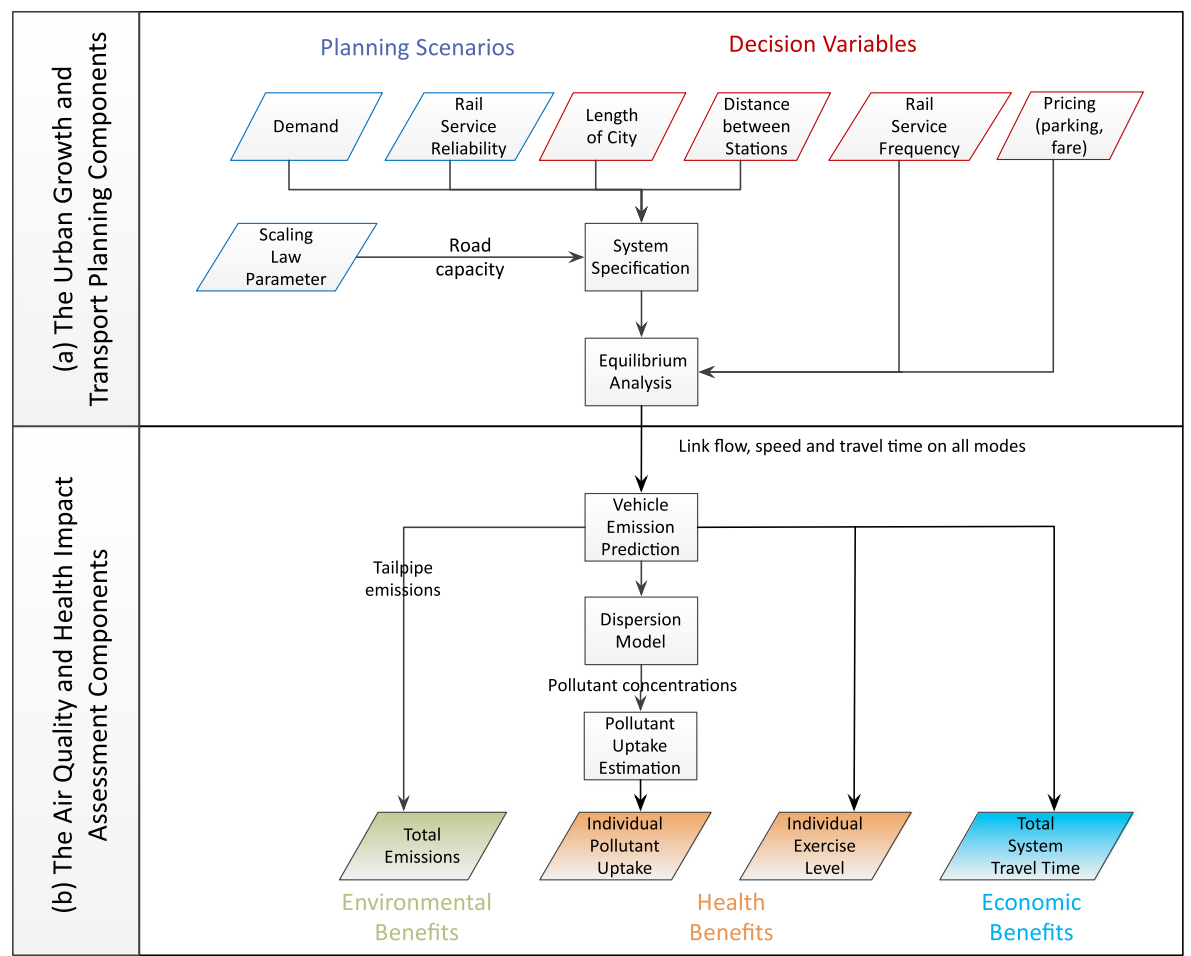

Fig. 2 An overview of the modelling suite of urban growth, transport planning, air quality and health impact assessment components 
the demand; or (2) invest in more sustainable alternative modes of transport, such as rail, that can be accessed by walking and cycling. Obviously, combinations of the two strategies at different investment levels can also be considered. In terms of urban growth strategies, planners might consider restricting urban development to be within certain areas, like the Green Belt in the UK, such that rail supply can be supported by higher demand generated from intensification with mixed development.

As shown in the overview of the modelling suite in Fig. 2, we will need a system specification that represents both the transport investment and urban growth strategies. In this model, the structural design variables include the length of the city and distance between stations. Typically we can assume a catchment distance of about $1 \mathrm{~km}$ to the rail station by walking and $5 \mathrm{~km}$ by bicycle. Residents are located continuously along the corridor and they can all access the rail service by walking and cycling to the nearest station, or access the highway at any point. Note that for simplicity, we do not include park-and-ride or passenger drop-off by car as an access mode here. That is, residents only have two mode choices, car or rail. This system can be represented conceptually as shown in Fig. 3 .

\subsubsection{Equilibrium Analysis}

Once we have a system specification, the next planning question is what level of service to be offered at what price on each mode. The ultimate objective is to provide a system that will bring the highest level of benefits in all aspects, including economic, environmental and health. The performance of the system in turn depends on how users might respond to the choices available. Therefore, it will be vitally important to be able to forecast the demand on the two different modes at different locations of the city. This requires a choice model that can predict realistically the travel behaviour of users in terms of mode choice. As mentioned earlier, travel time reliability, is one of the two most important dimensions of the journey that affect the overall satisfaction on rail (Brons and Rietveld 2009). On the other hand, travel time, travel time reliability and monetary costs are considered as the three most important factors influencing route choice behaviour on a road network (e.g. Abdel-Aty et al. (1995), Lam and Small (2001), and Li et al. (2010)).

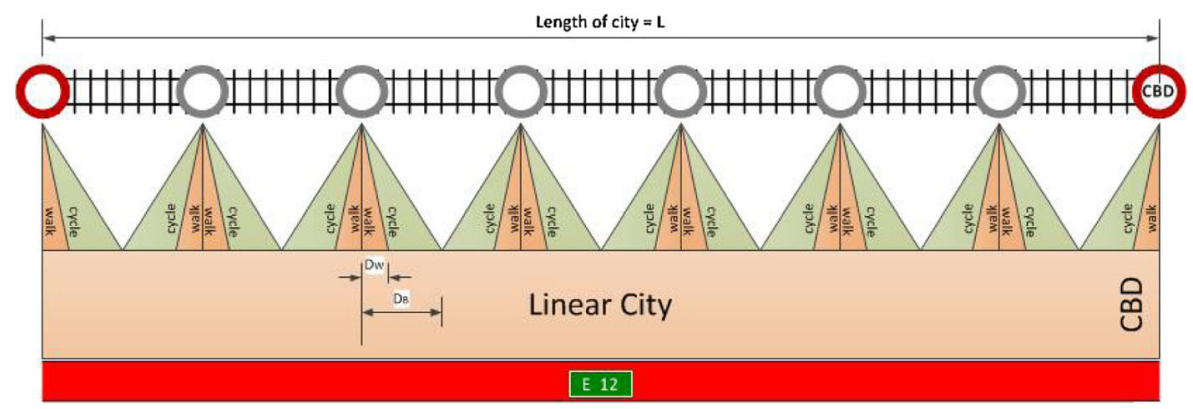

Fig. 3 A schematic design of a linear monocentric city 
A lot of research effort has been put into developing reliability-based assignment models in both road networks (e.g. Lo et al. (2006) and Watling (2006)) and transit networks (e.g. Szeto et al. (2013) and Yang and Lam (2006)). These models essentially look at the effect of travel time reliability on route choice behaviour within either a road network or a transit network. Since travel time reliability, however, is also an important factor influencing mode choice, naturally this leads to a combined mode and route choice approach (Fu et al. 2014). Fu et al. (2014) applied a reliabilitybased user equilibrium (RUE) approach in a multi-modal network to determine the mode and route choice, assuming that all users have a common objective of minimising a route (dis)utility function based on travel time budget (TTB) (Lo et al. 2006).

As discussed in Wang and Ehrgott (2013) and Wang et al. (2014a), the existing network equilibrium models (including RUE models), as identified earlier, share the common feature that the objectives of minimising cost, time and (un)reliability are combined into a single objective, which is either in the form of a generalised cost or (dis)utility function. The use of a single objective in network equilibrium models has restricted their capability to model some rational choices, which cannot be chosen under this modelling framework, but might have been chosen in reality as they are considered to be rational choices from a multi-objective point of view.

Let us look at the implications of applying a single-objective user equilibrium mode choice model in a linear monocentric city. This is in fact quite a well studied problem as reviewed in Huang et al. (2014). In a linear monocentric city the congestion level on the road network will only increase towards the CBD. This leads to the classical watershed case (Jehiel 1993) that commuters living farther away from the CBD beyond this indifferent point will all take the car. Thus, in the bi-modal case, as in Huang et al. (2014), there always exists a location whereby the generalised cost or the TTB is indifferent between the two modes. There are other studies that considered more than two mode choices in the literature. Wang et al. (2004) studied the optimisation of a single park-and-ride location problem in a linear monocentric city. Wang et al. considered the user equilibrium between three modes: (1) rail only; (2) park-and-ride to catch rail; and (3) car only. Liu et al. (2009) subsequently studied the case of a continuum park-and-ride location problem where multiple park-andride facilities can be located anywhere along the corridor. Both models are based on minimisation of the conventional generalised cost function which is a linear combination of travel time and monetary cost. Wang and Du (2013) then proposed a RUE model by applying the concept of TTB in Lo et al. (2006) to optimise a single parkand-ride location in a linear monocentric city. Wang and Du assume that all users want to minimise TTB subject to a reliability threshold. All of these models define equilibrium based on a single objective.

Now in the proposed system as described in Section 2.1.1, for some locations, rail might be more expensive and take longer time but it might also be the most reliable mode of transport. From a multi-objective optimisation point of view, rail can still be a more attractive alternative compared to car for some people, as long as it is not dominated by car in terms of all qualities, i.e. travel time, travel time reliability and monetary cost. However, in all the standard formulations for bi-modal equilibrium in a linear monocentric city mentioned above, the generalised cost or TTB on rail would 
have appeared to be higher for all residents living farther away from the CBD beyond a certain point, as in the watershed case. In other words, even though rail might be a rational choice based on multi-objective optimisation concept, the single-objective formulation will predict that no one is going to choose it beyond this indifference point. This is an unrealistically restrictive constraint on the model, which is relaxed in this paper.

With the proposed equilibrium analysis model, we overcome this difficulty by applying a bi-modal three-objective user equilibrium (TUE) model. This TUE concept is introduced in Wang and Ehrgott (2017), developed based on concepts introduced in Wang and Ehrgott (2013) and Wang et al. (2014a). This new equilibrium model permits a more general concept of equilibrium based on the simultaneous consideration of all three objectives separately, thereby overcoming the unrealistic limitations of standard equilibrium models for a linear monocentric city.

All users are assumed to have three objectives: (1) minimise travel time; (2) maximise travel time reliability; and (3) minimise monetary cost. In this case, when faced with the two alternatives, car or train, a user will consider the monetary cost alongside the departure time at which they will need to leave in order to achieve their desired arrival time reliability.

Different travel time distributions can be considered for each mode, along with different distributions of desired reliability amongst the population of travellers. In this paper we assume that rail has (fixed) reliability of $95 \%$ and fixed travel time, whereas car travel times are described by a continuous non-negative distribution (details in 3.1) whose mean and variance increase with congestion. Each user has his/her own threshold of travel time reliability, which is defined as the probability of arriving at the destination within an allocated TTB (Lo et al. 2006). We assume travellers' desired level of reliability is uniformly distributed between $50 \%$ and $95 \%$ at every location throughout the LMC; $50 \%$ and $95 \%$ represent the two extreme cases of risk neutral and risk averse, respectively. A user will work out the required TTB in order to satisfy his/her own desired level of reliability and hence decide his/her preference based on the trade-off between the monetary costs and the required TTBs for the two options. Note that if we included travellers demanding $>95 \%$ reliability, they would be restricted to only car (and likely require very high TTB); such fixed-mode travellers are of less interest.

One would expect that as the road network becomes both more congested and more unreliable, rail would become more attractive, in the sense that even though the door-to-door travel time may be longer, one might prefer to take the train instead of driving as long as the rail service punctuality outperforms the travel time reliability on the road network. To model how individuals might trade-off between the required TTBs and monetary costs, we apply the travel time budget surplus (TBS) concept introduced in Wang and Ehrgott (2017), further developed from the time surplus concept introduced in Wang and Ehrgott (2013). We assume that for any given price (monetary cost), an individual will have a maximum TTB that he/she would be willing to spend. Naturally, the higher the price, the less time will be willing to be spent. This becomes the indifference curve for this individual, as shown in Figs. 4 and 5, meaning that along this curve, the alternatives are equally attractive. Note that this formulation allows for nonlineear indifference curves; convex or concave curves 


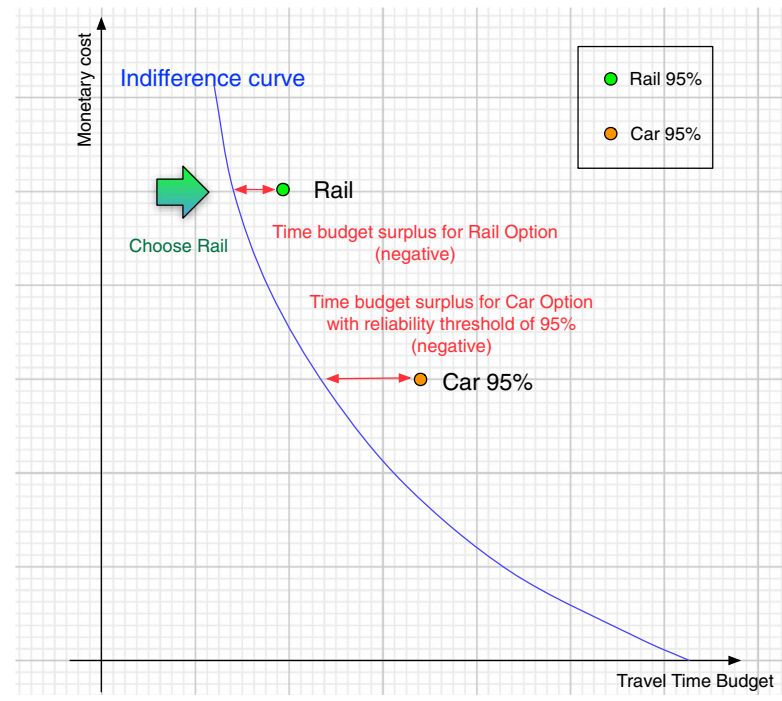

Fig. 4 Illustration of TBS concept: Rail is preferred

could be used. We define TBS as the maximum TTB minus the required TTB for the desired level of reliability. An individual would choose the option with the highest TBS. For example, as shown in Figs. 4 and 5, a user with reliability threshold of 95\% will choose rail while a user with reliability threshold of $50 \%$ will prefer to drive. An equilibrium is reached when no individual can improve his/her TBS by switching mode. This is called the travel time budget surplus maximisation three-objective user equilibrium (TBSmaxTUE) condition.

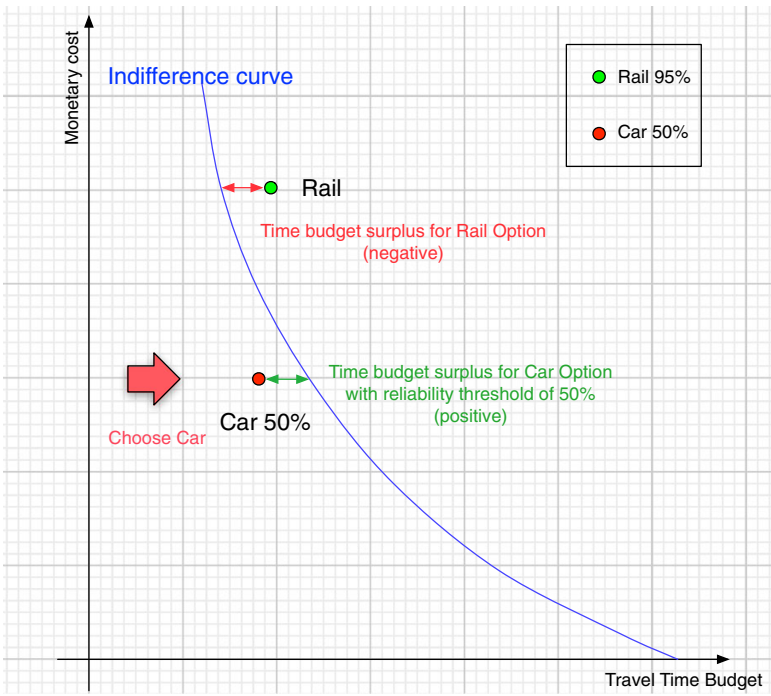

Fig. 5 Illustration of TBS concept: Car is preferred 
At each location, the equilibrium modal split can be all different and it will follow this equilibrium condition. There are three possible outcomes: (1) all residents from this location will use rail; (2) all residents from this location will use car; and (3) some residents will use rail and some will use car.

Based on the TBSmaxTUE condition, we can determine the conditions for these three outcomes based on the TBS for car at different reliability threshold values, compared with that for rail which has a fixed given reliability of say $95 \%$, as illustrated in Figs. 6, 7 and 8. Note that we assume that rail is the most reliable mode. Thus, the travel time reliability of car can only be in the range of [50\%, 95\%]. Now to determine the modal share, it would be a matter of comparing the TBS for rail with those for car: the highest achievable TBS at 50\% threshold; and the minimum possible achievable TBS at $95 \%$ threshold. As illustrated in Fig. 8, when TBS $_{\text {Rail }}^{95 \%}$ is in between these two values, then both rail and car will have positive modal shares and the modal split is dependent on the distribution of threshold values at this location. It is interesting to note that, as shown in Fig. 8, at this indifferent threshold value (denoted as $r \%$ ), the equilibrium TBS for car is equal to that of rail. Here we assume that travel time reliability on road is flow dependent. Thus the traffic volume on road at equilibrium modal split will also give us the TTB value corresponding to the equalised TBS value for car, as illustrated in Fig. 8.

\subsection{The Air Quality Modelling and Health Impact Assessment Components}

From equilibrium analysis, as described in Section 2.1.2, we can obtain the modal split between the two modes at each location along the city. Based on the modal

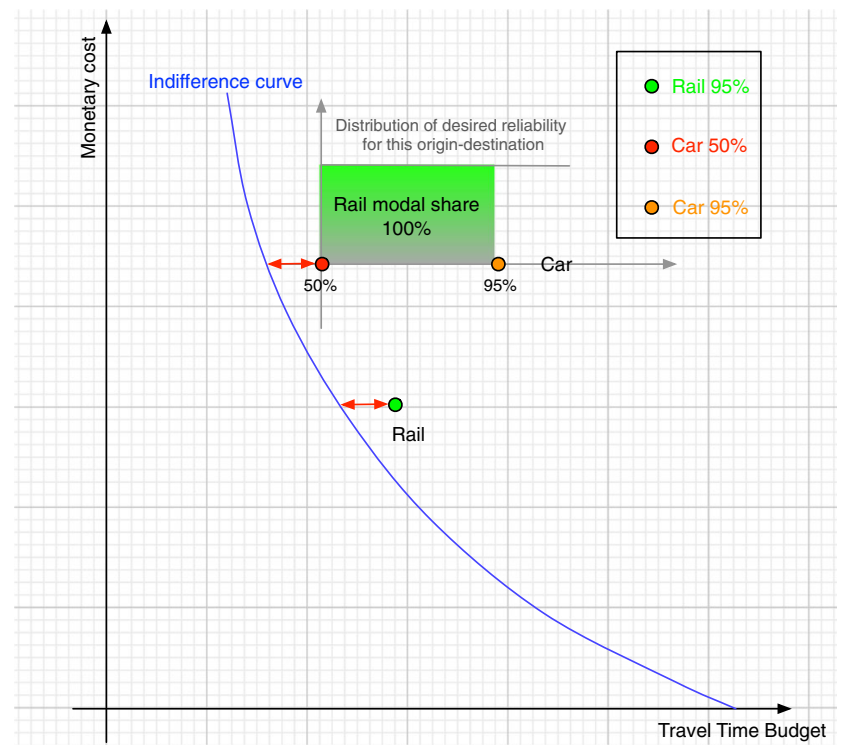

Fig. 6 Case 1(a): Rail only 


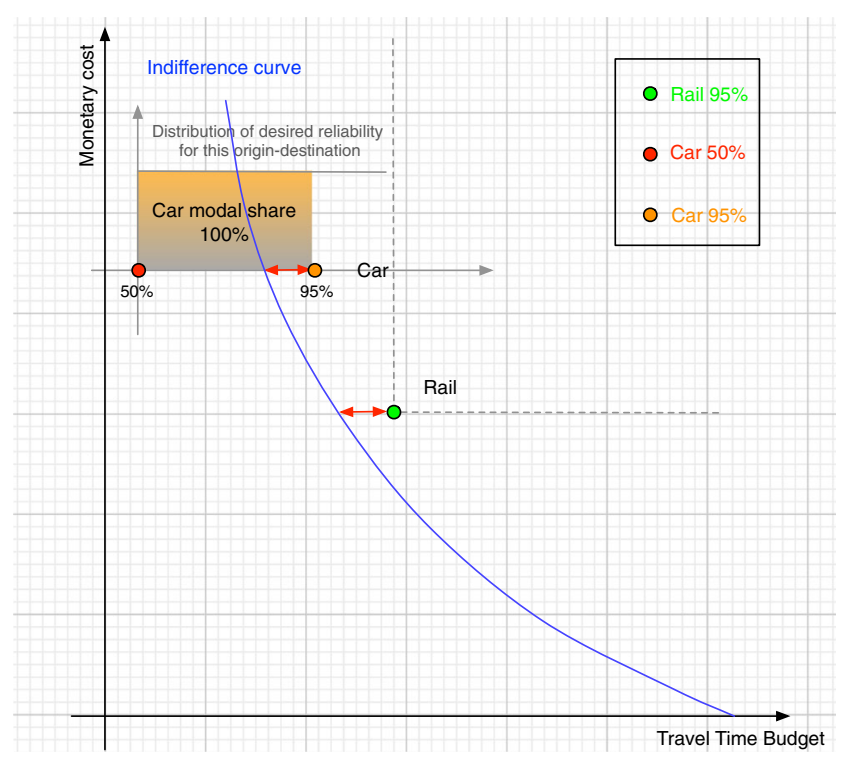

Fig. 7 Case 1(b): Car only

split, we can then derive the link flow, average speed and travel time on all modes (including not only car and rail, but also the access modes, walking and cycling). The next stage is to determine at each location, the environmental and health impact as a result of the choices made by the residents at equilibrium, as shown in Fig. 2b. Here we adopt a three-stage approach to model the pollutant uptake during the commute (Wang et al. 2014b):

1. Vehicle Emission Prediction Model (VEPM) - modelling emission rates for the road based on traffic flow and average vehicle speed (Energy \& Fuel Research Unit The University of Auckland 2008).

2. Dispersion model - modelling air pollutant concentrations from road emission rates and surface meteorology (Dirks et al. 2002, 2003).

3. Pollutant uptake estimation - modelling pollutant uptake from air pollution concentrations and the travel time along each link in the commute including the active mobility component (Dirks et al. 2012).

It is important to note that (Dirks et al. 2012)'s pollutant uptake function is based on the following principle:

Pollutant uptake $=$ Pollutant concentration $\times$ Link travel time $\times$ Breathing rate

By applying Dirks et al.'s model, we will be able to estimate individual pollutant uptake, by aggregating the pollutant uptake on different modes (including access modes, walking and cycling) during the journey to work. As highlighted earlier, this is an important measure of the impact of air quality on health that cannot be ignored, as the breathing rate during exercise can be up to $2-3$ times resting breathing rate 


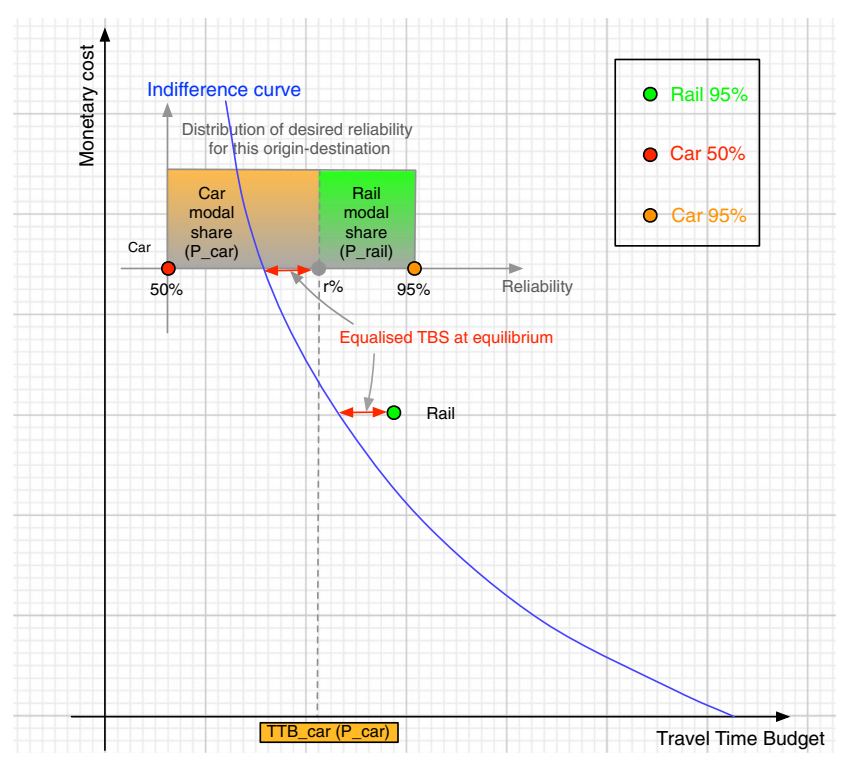

Fig. 8 Case 1(c): Both car and rail have positive modal shares

(Dirks et al. 2012). Similarly, we can also keep track of the total time of each individual being active during his/her journey to work, which is the link travel time on either of the two access modes, walking or cycling.

\subsection{System Performance Analysis}

To assess system performance, we perform both spatial and overall system performance assessment, as well as analysis at an individual level. For economic and environmental impact, we apply the conventional approach of measuring the total system travel time and total emissions as a proxy variable for environmental impact from tailpipe emissions. In terms of health impact, it is meaningful to perform the analysis at an individual level. As described in Sections 2.1 and 2.2, we first start with an equilibrium analysis of mode choice decisions made by residents. We then perform spatial analysis of emission levels as well as pollutant concentrations. Finally, we can determine the total pollutant uptake as well as the total time each individual being active during journey to work. Now to measure the performance of the system in terms of impact on health, we will need to look at the population distribution of pollutant uptake level as well as the time being active. Here we introduce two new measures: (1) median or maximum pollutant uptake during journey to work; and (2) percentage of population achieving a minimum level of physical activity, for example, being active for at least 10 minutes. 


\section{Mathematical Formulation}

Consider a corridor city, $x \in[0, L]$, with the CBD at location $x=L$. Total travel demand in the city arises from the population of commuters $Q$. These commuters are continuously distributed along the corridor with constant density $q=Q / L$.

We consider two modes for morning commuting: driving in private car on the highway (denoted $C$ ) or taking the train $(T)$. All commuters can access the highway everywhere along the corridor. Commuters access the railway at the most convenient nearby station which is reached by an active mode, walking or cycling, depending on the distance to the station. For commuters living close to the $\mathrm{CBD}$, it may be more efficient to walk or cycle directly to the CBD. We will use 'train' as shorthand for all non-car commuters, including those using only an 'access' mode.

At each location, $x$, the proportion choosing car versus train is $p_{C}(x)$ and $p_{T}(x)$ respectively with $p_{T}(x)+p_{C}(x)=1$.

We assume that the population of travellers have different risk preferences, with the desired reliability at each location continuously uniformly distributed between $50 \%$ and $95 \%$.

\subsection{Travel Time, Travel Cost and Travel Time Reliability}

Train Travel Time We consider the case when the railway is congestion free. Travel time by train from location $x$ to the CBD (at $x=L$ ) comprises the following components:

- access time to the most efficient (not necessarily nearest) station, $s(x)$, by walking/cycling, $T_{A}(x, s(x))$

- bike parking time if cycling, $T_{B P}$

- waiting time for the train, $W_{T}$, (depends on service frequency)

- train travel time to the CBD

- $\quad$ egress time (includes walking time from station to office), $E_{T}$

We will deal with these components in turn.

Consider $N_{S}$ stations located at $S=\left\{s_{i}: i=1, \ldots, N_{S}\right\}$. Rather than simply going to the nearest station, it may be more attractive to cycle/walk slightly further to a station which is closer to the $\mathrm{CBD}$, since this reduces train travel time to the $\mathrm{CBD}$ and hence the total trip time. Of the stations closer to the CBD, the nearest one to $x$ is simply $s^{+}(x)=\min _{s_{i} \in S}\left\{s_{i}: s_{i} \geq x\right\}$. Whereas the nearest station further away from the CBD is $s^{-}(x)=\max _{s_{i} \in S}\left\{s_{i}: s_{i} \leq x\right\}$.

Travel time to the station by walking/cycling is derived from the walking speed ( $f_{W}$ in minutes per $\mathrm{km}$ ) or bicycle speed $\left(f_{B}\right.$ in minutes per $\mathrm{km}$ ) as appropriate. If travelling by bike we add an extra "bike parking" time delay, $T_{B P}$, which also serves to ensure that active mode travel time is strictly increasing with distance. Travel time by active mode from $x$ to $y$ is

$$
T_{A}(x, y)=\left\{\begin{array}{cl}
|x-y| \times f_{W} & \text { walk if }|x-y| \leq D_{W} \\
|x-y| \times f_{B}+T_{B P} & \text { bike if } D_{W}<|x-y| \leq D_{B}
\end{array}\right.
$$


where $D_{W}, D_{B}$ are the maximum walking and biking distances respectively. For commuters living near the CBD it may be quicker to walk/cycle directly to the CBD rather than incur the waiting time at the station and egress time from the CBD station. The active mode travel time directly to the CBD is $T_{A}(x, L)$.

For non-car commuters we compare these alternatives: (i) walk/cycle to nearest station and take train, (ii) walk/cycle to nearest 'forward' station (closer to the CBD than starting location) (iii) walk/cycle direct to the CBD (if less than $10 \mathrm{~km}$ ). Note that option (iii) of using only an active mode has zero money cost and (we assume at least) $95 \%$ reliability. Hence when this 'active mode only' option has minimum expected travel time and zero cost it dominates the train options (i) and (ii).

The total travel time by active mode and train from location $x$ to the CBD is

$$
T_{T}(x)=\min \left\{\begin{array}{l}
T_{A}\left(x, s^{-}(x)\right)+W_{T}+\int_{s^{-}(x)}^{L} f_{T} d w+E_{T} \\
T_{A}\left(x, s^{+}(x)\right)+W_{T}+\int_{s^{+}(x)}^{L} f_{T} d w+E_{T} \\
T_{A}(x, L)
\end{array}\right\}
$$

where $W_{T}$ is the train waiting time (taken to be half the headway), $f_{T}$ is the constant travel time per unit distance $(\mathrm{km})$ by train and $E_{T}$ is egress time from the central station. The "train" mode comprises the minimum time alternative from $T_{T}(x)$ above and hence includes walking/cycling direct to the CBD when this is quicker than taking the train. For simplicity of notation we denote the used station, that minimises $T_{T}(x)$, as $s(x)$. Recall that by assumption the active mode with train provides (fixed) $95 \%$ reliability.

Train Monetary Cost The rail ticket price is proportional to distance (from the station, $s(x))$ to the CBD. With $m_{T}$ as the per km monetary cost for train travel the total money cost $M_{T}(x)$ to travel by train from $x$ to the CBD is

$$
M_{T}(x)=m_{T} \times[L-s(x)]
$$

Travellers taking only an active mode for their whole journey will incur zero money cost.

Car Travel Time Travel time on the highway depends on congestion arising from traffic volume $v$. Using the BPR function, the expected travel time per unit distance is given by

$$
t_{C}(v)=f_{C} \times\left[1+0.15\left(\frac{v}{c_{C}}\right)^{4}\right]
$$

where $f_{C}$ is the free-flow travel time (minutes per $\mathrm{km}$ ). For simplicity we will consider capacity, $c_{C}$, to be constant along the entire highway, though the model formulation allows for this to vary. The traffic volume at location $x$ is determined by the number of commuters choosing car, $p_{C}(x)$, from city boundary (at $x=0$ ) up to location $x$. Therefore $v=v(x)$ with

$$
v(x)=\int_{0}^{x} p_{C}(w) q d w
$$


and hence the expected travel time by car from $x$ to the CBD is

$T_{C}(x)=\int_{x}^{L} t_{C}(v(w)) d w+T_{C P}=\int_{x}^{L} f_{C} \times\left[1+0.15\left(\frac{\int_{0}^{w} p_{C}(z) q d z}{c_{C}}\right)^{4}\right] d w+T_{C P}$

We add the constant $T_{C P}$ for the time required to park the car.

Car Travel Time Reliability We assume that the car travel time from location $x$ to the CBD is stochastic, with mean $T_{C}(x)$ as defined above. Following Taylor and Susilawati (2012), we represent the car travel time distribution using a Burr XII distribution, having PDF:

$$
\phi(t \mid \alpha, c, k)=\frac{c k}{\alpha}\left(\frac{t}{\alpha}\right)^{c-1}\left(1+\left(\frac{t}{\alpha}\right)^{c}\right)^{-(k+1)} \text { for } t>0, \alpha>0, c>0, k>0
$$

and corresponding cumulative distribution function $\Phi(t \mid \alpha, c, k)$. The mean value, $\mu$, is

$$
E(t \mid \alpha, c, k)=\mu=\frac{\alpha k \Gamma\left(k-\frac{1}{c}\right) \Gamma\left(1+\frac{1}{c}\right)}{\Gamma(k+1)} .
$$

Note that for fixed shape parameters, $c, k$, the scaling parameter, $\alpha$, determines the mean. The variance of this travel time distribution is

$$
\operatorname{Var}(t \mid \alpha, c, k)=\frac{\alpha^{2} k \Gamma\left(k-\frac{2}{c}\right) \Gamma\left(1+\frac{2}{c}\right)}{\Gamma(k+1)}-\mu^{2} .
$$

Note that for most choices of $\alpha, k, c$, the Burr distribution is typically skewed; the mean does not coincide with the 50th percentile. We fix the shape parameters $c, k$. For each location $x$, the travel times from $x$ to the CBD comprise a Burr distribution with mean set to be $T_{C}(x)$, by choosing the value of $\alpha$ appropriately, using Eq. 8 . This results in the standard deviation (from Eq. 9) scaling linearly with the mean (Figs. 9 and 10).

Car Monetary Cost We consider parking charges $\left(P_{C}\right)$ and fuel costs only. We could include fuel costs according to travel time/speed to take account of the congestion impact on fuel use, but for this simple case we have a fixed cost per $\mathrm{km}\left(m_{C}\right)$ for fuel. The monetary cost of travel by car from $x$ to the CBD is:

$$
M_{C}(x)=P_{C}+m_{C} \times[L-x] .
$$

\subsection{Travel Time Budget Surplus Mode Choice}

With the preceding specification, consider travelling from location $x$ to the CBD.

Travel by train costs $M_{T}(x)$ and the travel time is $T_{T}(x)$, with reliability of $95 \%$. This includes the case of travelling by active mode directly to the CBD when this is quicker (from Eq. 2). Therefore for all travellers, regardless of reliability preferences, the travel time budget for train is $T T B_{T}(x)=T_{T}(x)$, 


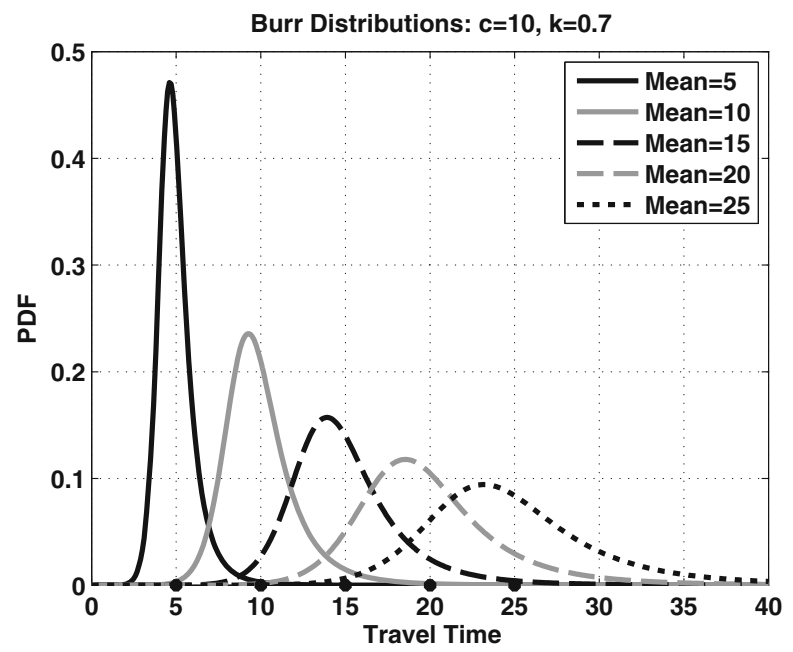

Fig. 9 Burr Distributions [c=10, $k=0.7]$

Travel by car costs $M_{C}(x)$. Car travel times comprise a Burr distribution with mean $\mu=T_{C}(x)$, which corresponds to scaling parameter $\alpha\left(T_{C}(x)\right)$, calculated from Eq. 8. The probability of car travel time from location $x$ to the CBD being less than $t$ is $\Phi\left(t \mid \alpha\left(T_{C}(x)\right), c, k\right)$. Any desired level of reliability $r \in[0.50,0.95]$ therefore corresponds to a travel time budget that can be computed from the inverse CDF:

$$
T T B_{C}(x, r)=\Phi^{-1}\left(r \mid \alpha\left(T_{C}(x)\right), c, k\right) .
$$

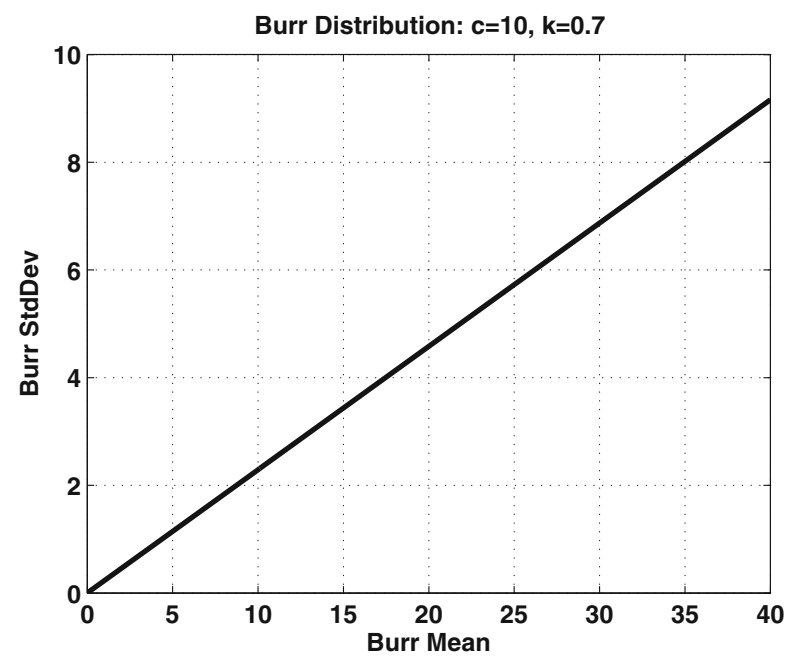

Fig. 10 Burr Distribution Mean vs Standard Deviation 
As described in Section 2.1.2, mode choice is based on maximising the travel time budget surplus with reference to a time-money indifference curve. Therefore an indifference curve needs to be specified at each location, as part of the model specification. Clearly a variety of indifference curves can be proposed and used within this model formulation. For the purposes of this paper the indifference curve at location $x$ is assumed to be negative exponential, and is defined by specifying two time-money reference points, $(m, t)$, that this curve passes through:

- $\quad t=T_{A}(x, L)$ and $m=0$ corresponding to travelling by active mode to the CBD for free

- $\quad t=(L-x) f_{T}$ and $m=(L-x) \tau$ corresponding to travelling at the car free flow speed to the CBD at the cost of paying the toll of $\tau$ (in $£ / \mathrm{km}$ ).

The toll $\tau$ is not implemented, it is a hypothetical fixed per $\mathrm{km}$ toll that commuters would be willing to pay in order to achieve free flow travel speed for their entire journey. This results in an indifference curve for each location $x$ :

$$
I(m ; x)=T_{A}(x, L) \exp \left\{\frac{m}{(L-x) \tau} \log \left(\frac{(L-x) f_{T}}{T_{A}(x, L)}\right)\right\} .
$$

Using the indifference curve defined at location $x$, travellers decide between car and train alternatives by maximising their travel time budget surplus:

$$
\begin{gathered}
T T B S_{T}(x)=I\left(M_{T}(x) ; x\right)-T T B_{T}(x), \\
T T B S_{C}(x, r)=I\left(M_{C}(x) ; x\right)-T T B_{C}(x, r) .
\end{gathered}
$$

At each location, the TTBS for train is constant across all travellers. The TTBS for car comes from Eq. 11 and depends on the desired reliability which is uniformly distributed at each location. Money costs for train and car come from Eqs. 3 and 10 respectively.

Travellers will choose the mode which maximises their TTBS. Recall that at each location there is a uniform distribution of reliability preferences $r \in[0.50,0.95]$. Figures 6, 7, and 8 illustrate the possible mode choice outcomes. At location $x$, the reliability preference, $r$, that gives $T T B S_{C}(x, r)=T T B S_{T}(x)$ will be

$$
\tilde{r}(x)=\Phi\left(\left[I\left(M_{C}(x) ; x\right)-T T B S_{T}(x)\right] \mid \alpha\left(T_{C}(x)\right), c, k\right) .
$$

Note that the mean of the car travel time distribution depends on the highway flow, via $T_{C}(x)$, and hence on the modal split $p_{C}(x)$. By contrast, $I\left(M_{C}(x) ; x\right)$ and $T T B S_{T}(x)$ do not change with $p_{C}(x)$. It will be helpful to explicitly recognize this:

$$
\tilde{r}(x)=\Phi\left\{\left[I\left(M_{C}(x) ; x\right)-T T B S_{T}(x)\right] \mid \alpha\left(f_{C} \int_{x}^{L}\left[1+0.15\left(\frac{\int_{0}^{w} p_{C}(z) q d z}{c_{C}}\right)^{4}\right] d w+T_{C P}\right), c, k\right\} .
$$

The proportion choosing car is then

$$
p_{C}(x)= \begin{cases}1 & \text { if } \tilde{r}(x)>0.95 \\ \tilde{r}(x)-0.50 & \text { if } 0.50<\tilde{r}(x) \leq 0.95 \\ 0.95-0.50 & \text { if } \tilde{r}(x) \leq 0.50\end{cases}
$$


and by definition, $p_{T}(x)=1-p_{C}(x)$.

By substituting $\tilde{r}$ from Eq. 16, this is the equilibrium formulation summarised as a fixed point problem. Travellers will compare the car and train alternatives and seek to maximise their travel budget surplus, by consulting their indifference curve, with reference to their desired level of reliability. Each traveller will switch mode if they can improve their TTBS. We achieve equilibrium when no traveller can increase their TTBS by changing mode.

Emission, Dispersion, Uptake Models Road traffic gives rise to harmful emissions including $\mathrm{CO}, \mathrm{NOx}$ and particulates. In this modelling framework emissions do not affect individual travel choices, they result from them. Emissions and their health impacts are considered within the upper level assessment of system performance. Here we focus only on $\mathrm{CO}$, although clearly the approach could easily be extended to include additional emissions predictions, providing further performance indicators for policy makers to consider alongside one-another.

Rilett and Benedek (1994) give the rate of production (ROP) of CO in grams/(veh ft) as

$$
R O P=0.0033963 \exp (0.01456 V) \frac{1}{V}
$$

when the vehicle velocity, $V$, is in $\mathrm{ft} / \mathrm{sec}$.

Assuming all the CO production is from cars, with vehicle flow $v(x)$ in veh/hr and instantaneous travel time $t_{C}(v(x))$ in $\mathrm{min} / \mathrm{km}$, at location $x$ the instantaneous ROP in $\operatorname{grams} /(\mathrm{km} \mathrm{sec})$ is

$$
R O P(x)=\frac{1}{60} 0.0033963 \exp \left(0.01456 \frac{3280.8399}{60 t_{C}(v(x))}\right) t_{C}(v(x)) v(x) .
$$

The total production of $\mathrm{CO}$ is then $\int_{0}^{L} R O P(x) d x$ in grams/sec.

Following Dirks et al. $(2002,2003)$ the emission concentration at $x$ in g/cu.m is $E(x)=R O P(x) /(60 \times 1000 \times 2.1)$, assuming windspeed of $2.1 \mathrm{~m} / \mathrm{s}$ and dispersion throughout the urban corridor up to a height of $60 \mathrm{~m}$.

Individual CO uptake is computed (Dirks et al. 2012) based on activity-based breathing rate (in cu.m/min), the location-specific emissions concentration and the time spent at each location, i.e. the speed of travel. Resting breathing rate is taken to be $B_{R}=0.012 \mathrm{cu} . \mathrm{m} / \mathrm{min}$ which doubles for walking $\left(B_{W}=0.024 \mathrm{cu} . \mathrm{m} / \mathrm{min}\right)$ and triples for cycling ( $B_{B}=0.036 \mathrm{cu} . \mathrm{m} / \mathrm{min}$ ). The pollutant uptake per person (in $\mathrm{g}$ ) for car drivers is then

$$
U_{C}(x)=\int_{x}^{L} E(w) B_{R} t_{C}(v(w)) d w .
$$

For those taking the train it is

$$
U_{T}(x)=\left|\int_{x}^{s(x)} E(w) \times\left\{\begin{array}{c}
B_{W} f_{W} \\
B_{B} f_{B}
\end{array}\right\} d w\right|+\int_{s(x)}^{L} E(w) B_{R} f_{T} d w
$$

depending on whether access mode to the station is by cycling or by walking. In the case of cycling/walking direct to the CBD the second integral is simply zero. The modulus sign is needed in case the used station is further from the CBD, $s(x)<x$. 


\subsection{Solution Algorithm}

First we list the necessary model parameters in Table 1.

The linear monocentric city is modelled as a continuum, which we solve by discretisation, splitting the interval $x \in[0, L]$ into $N$ elements so that $d x=L / N$. We will use the superscript $n$ to indicate vectors of the discretised problem that correspond to functions above.

Initialisation of Fixed Quantities The demand (veh/hr) arising from each of the $N$ locations is $q=Q / N$. For each location $x^{n}=n d x$ for $n=1, \ldots, N$ :

1. compute the station access times (to nearest 'forward' and 'backward' stations) from Eq. 1

2. compute the train travel time to the CBD, $T_{T}^{n}$, from Eq. 2 and the monetary cost, $M_{T}^{n}$, from Eq. 3

3. compute the car free flow travel time, and the car monetary cost, $M_{C}^{n}$, from Eq. 10

4. compute the walking/cycling time to the CBD from Eq. 1

5. generate the indifference curve $I^{n}(m)$ from Eq. 12

6. compute the travel time budget surplus for train $T T B S_{T}^{n}$.

The goal is to determine the mode split $\left\{p_{C}^{n}: n=1, \ldots, N\right\}$ such that no traveller can improve their TTBS by changing mode. The solution algorithm adopts the method of successive averages, and iteration $i$ of the mode split is labelled $p_{C}^{n}(i)$.

1. Set $p_{C}^{n}(i-1)=0 \forall n$ and the iteration counter $i=1$.

2. Compute the car flow from Eq. $5 v^{n}=\sum_{m=0}^{n} q p_{C}^{m}$

Table 1 Model Parameters

\begin{tabular}{lll}
\hline Parameter & Description & Default Value \\
\hline$L$ & City Length (km) & - \\
$s_{i}$ & Station Locations & - \\
$D_{W}, D_{B}$ & Maximum walking, cycling distance (km) & $0.5,10$ \\
$f_{C}, f_{T}, f_{W}, f_{B}$ & Speed (km/min) by car (free flow), train, walk, bike & $0.75,1.2,15,6$ \\
$Q$ & Total travel demand (persons/hr) & - \\
$W_{T}$ & Waiting time for train (min) & 15 \\
$E_{T}$ & Egress time (min) from station & 5 \\
$m_{T}, m_{C}$ & Cost (£/km) by train (ticket), by car (fuel) & $0.15,0.12$ \\
$\tau$ & Willing to pay (£/km) to get free flow speed & 1 \\
$c_{C}$ & Road capacity (veh/hr) & \\
$T_{C P}, T_{B P}$ & Parking time (min) for car, bicycle & $3,4.5$ \\
$P_{C}$ & Cost to park car (£) & 3 \\
$c, k$ & Burr Distribution shape parameters & $10,0.7$ \\
$B_{R}, B_{W}, B_{B}$ & Breathing rate (cu.m/min) resting, walking, cycling & $0.012,0.024,0.036$ \\
\hline
\end{tabular}




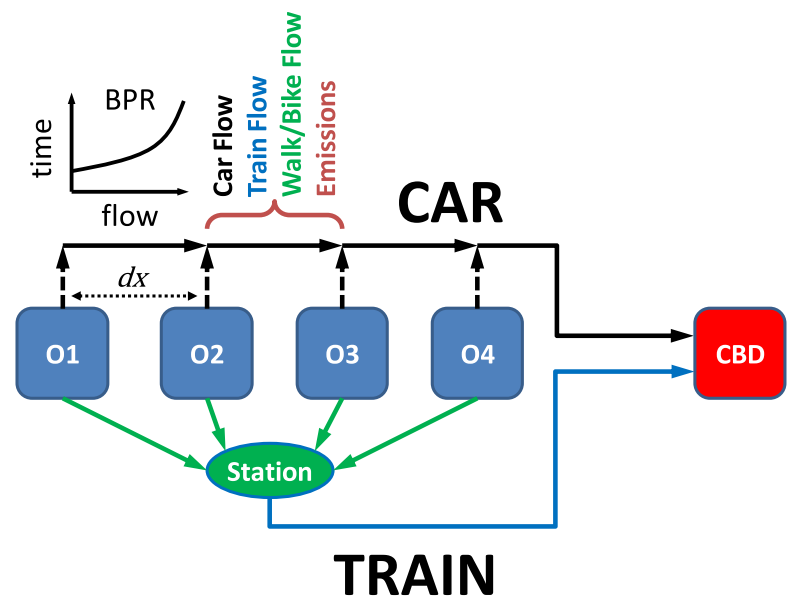

Fig. 11 Equivalent Network Assignment Problem

3. Compute the car travel time $t_{C}^{n}=t_{C}\left(v^{n}\right)$ from Eq. 4 and $T_{C}^{n}=T_{C P}+$ $\sum_{m=n}^{N} t_{C}^{m} d x$

4. Compute break-even car reliability from Eq. 15: $\tilde{r}^{n}=$ $\Phi\left(\left[I^{n}\left(M_{T}^{n}\right)-T T B S_{T}^{n}\right] \mid \alpha\left(T_{C}^{n}\right), c, k\right)$

5. Get new proportion wishing to use car from Eq. 16: $\tilde{p}_{C}^{n} \in$ $\left\{0,\left(\tilde{r}^{n}-0.50\right) /(0.95-0.50), 1\right\}$

6. $\quad$ MSA step: set $p_{C}^{n}(i)=p_{C}^{n}(i-1)+(1 / i)\left(\tilde{p}_{C}^{n}-p_{C}^{n}(i-1)\right)$

7. If converged stop, otherwise set $i=i+1$ and go to step 2 .

We check convergence by monitoring $\left\|p_{C}^{n}(i)-p_{C}^{n}(i-1)\right\|$.

Equivalent Network Assignment Problem We can re-cast the discretised problem as a 'standard' network equilibrium problem with $N$ origins and one common destination (the CBD), see Fig. 11. The highway comprises $N$ links in series, each link having strictly increasing separable BPR cost function. Constant cost centroid connectors can be used to contribute $T_{C P}$ to each car trip. The access mode and train combination comprise a second route for each OD pair. Note that for each location $x^{n}$ the rail alternative has fixed cost in both time and money, independent of mode choice, $p_{C}^{n}, p_{T}^{n}$, and hence independent of demand and flow. This discretised model can be admitted within the formulation presented in Wang and Ehrgott (2017) and hence solution by MSA is appropriate.

\section{Numerical Examples}

In this section, we present numerical examples to illustrate how the different components of the modelling suite as described in Section 2 can be applied to assess system performance of a linear monocentric city to support policy analysis. 
(a)

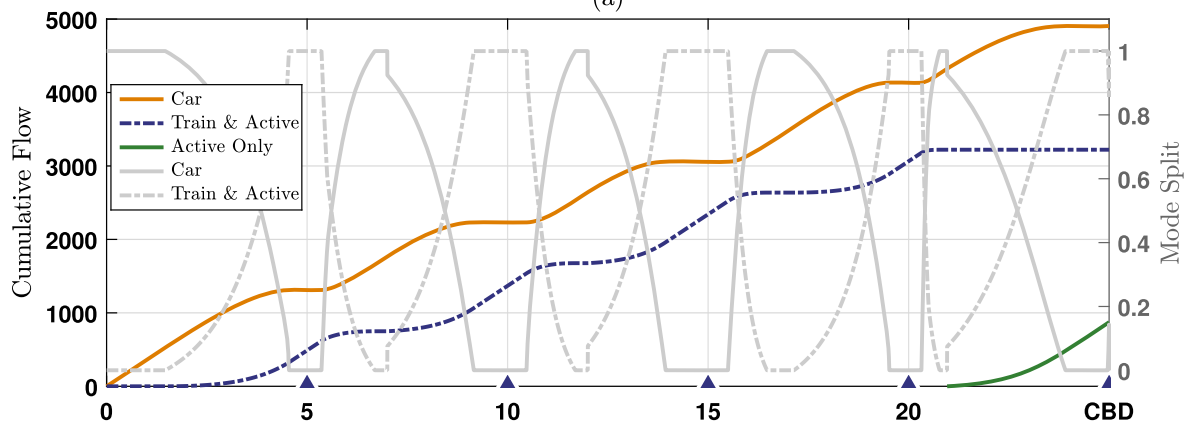

(b)

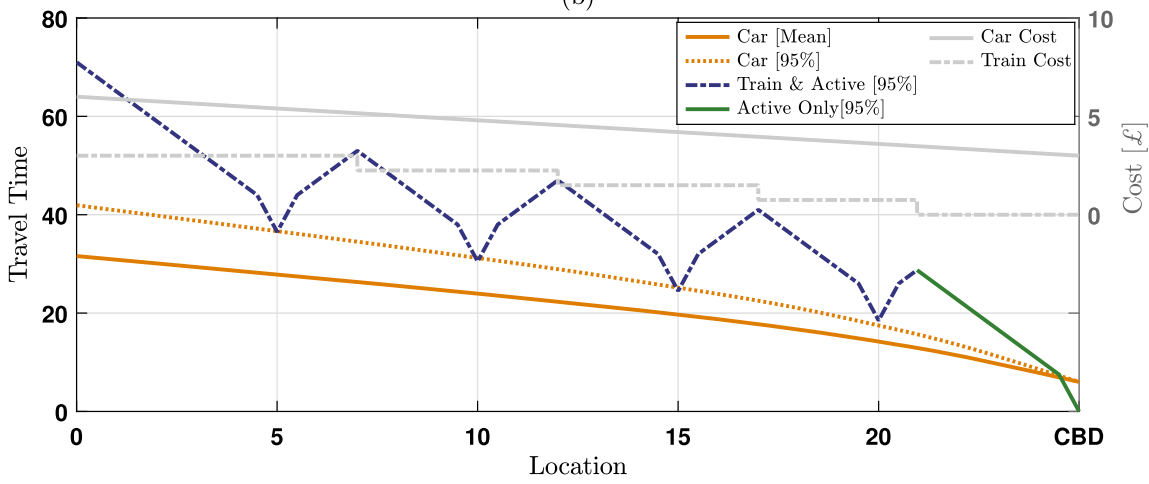

Fig. 12 a Cumulative Flow (coloured) \& Modal Split (grey); b Travel Time (coloured) \& Cost (grey)

\subsection{Spatial Analysis}

To illustrate the model, let us consider a $25-\mathrm{km}$ city with a highway of capacity 2,788 vehicles per hour. The peak demand is 9,000 trips per hour, about three times the capacity of the highway. Rail service is running at a frequency of 4 trains per hour. For simplicity, we assume that rail has unlimited capacity. There are 5 stations in total, evenly distributed along the city $5-\mathrm{km}$ apart from each other, with the terminus at the CBD.

\subsubsection{Equilibrium Analysis}

Equilibrium analysis for the $25-\mathrm{km}$ city as described above $(L=25 \mathrm{~km}, Q=$ $9000, c_{C}=2788$ ) is performed based on the TBSmaxTUE model, as described in Section 2.1.2, to determine the mode choice of residents originating from each location along the city considering the travel time, cost and travel time reliability on car and rail. The resulting cumulative flows, modal split and corresponding measures of health impact, i.e. level of physical activity and pollutant uptake of individuals from each location are illustrated in Figs. 12 and 13. Note that the CBD is located at the end of the corridor, i.e. at $25 \mathrm{~km}$ from the origin, while the boundary 

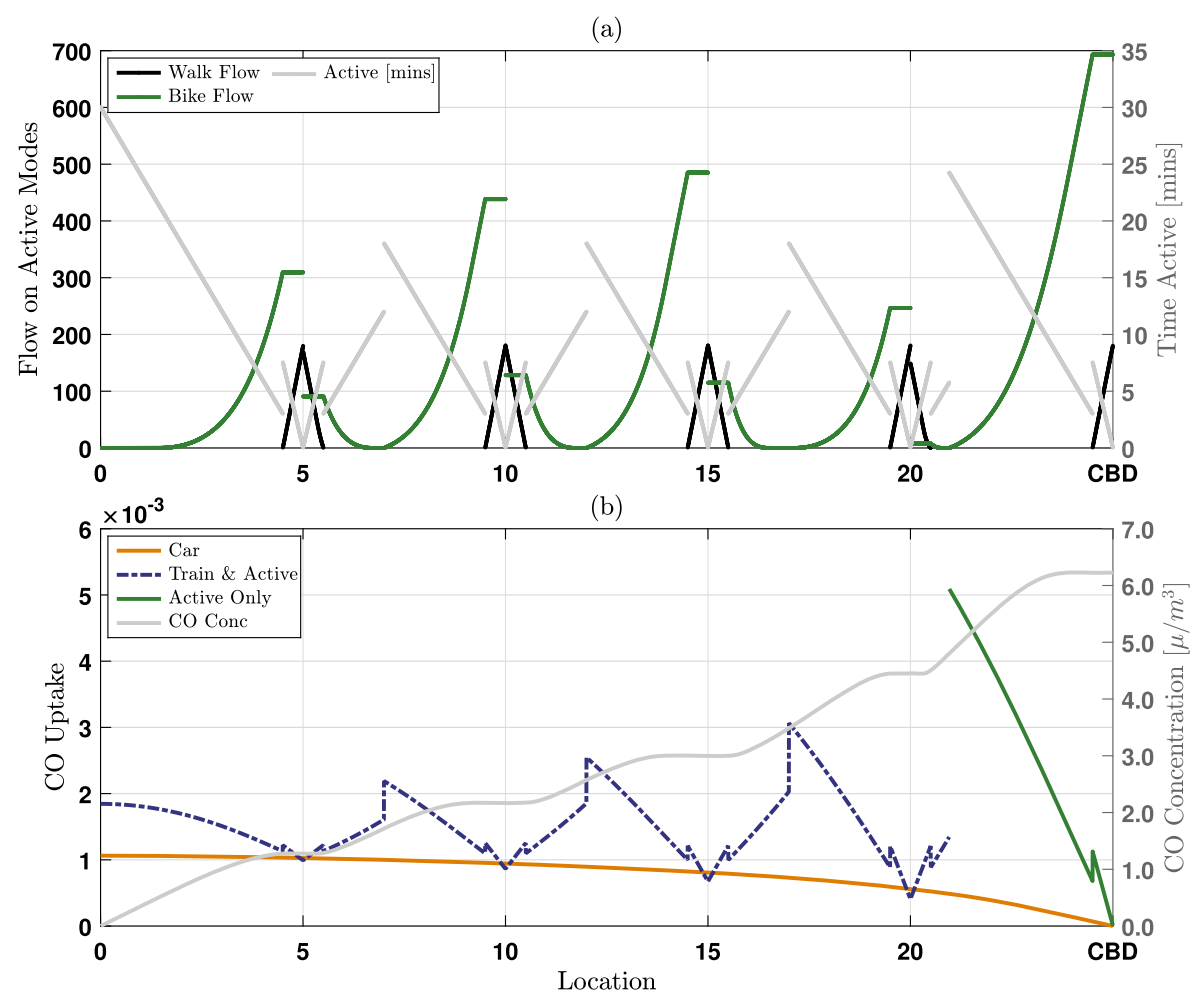

Fig. 13 a Flow on Active Modes \& Time Active (grey); b CO Uptake \& CO Concentration (grey)

of the city is at the origin. Station locations are coloured in blue on the x-axis of Fig. 12a.

Let us now explore the spatial pattern of mode choice decisions along the city and the resulting cumulative flows on car and rail, as illustrated in Fig. 12(a). With the road being empty at the boundary of the city, all residents at the boundary choose to drive. This corresponds to Case 1(b) 'Car only' in Fig. 7, where although car costs more it requires less travel time budget than rail for all traveller risk preferences. As we approach the first train station at location $5 \mathrm{~km}$, rail appeals to some travellers who live nearer to the station; they are attracted to the high travel time reliability offered by this mode as well as the lower cost. This corresponds to Case 1(c) 'Both car and rail have positive modal shares' in Fig. 8. Rail modal share then started to pick up and eventually all travellers living near the train station will take the train when the travel time budget on rail equals to that for the risk averse travellers, as shown in Fig. 12a. This corresponds to Case 1(c) 'Rail only' in Fig. 6.

As shown in Fig. 12a, this mode choice pattern (grey lines) repeats in a cyclical manner as we approach each train station. The closer a location is to the station, the higher the modal share on rail. This is indicated by the spikes of rail modal share that coincide with the station locations. Complementary to this, the spikes for car modal 
share appear to be at locations farthest away from the train station, around midway between stations.

There is another interesting observation as we approach the CBD, indicated in Fig. $12 \mathrm{a}$ and $\mathrm{b}$ by a green line, representing pure active modes (cycle or walk only) being chosen here. The green line in Fig. 12b illustrates locations from where it is faster to cycle or walk to the CBD directly rather than go "backwards" to the station at location $20 \mathrm{~km}$ and then take the train. Thus, in this zone near to the CBD, residents will either drive or cycle/walk to the CBD directly. Even closer to the CBD, all choose to cycle or walk due to shorter travel time and high reliability of the active modes (see mode split in Fig. 12a).

\subsubsection{Health Impact Analysis}

As discussed in Section 2.2, we measure health impact at an individual level in two aspects: (1) pollutant uptake; and (2) the time spent being active during the journey. Information on the flow on active modes, time being active and $\mathrm{CO}$ pollutant uptake level for trips generated from different locations are depicted in Fig. 13a and b.

Depending on the location, residents might choose to go in the "forward" or "backward" direction, whichever way that will minimise the access time plus the remaining journey time. The (cumulative) flows for walk and bike access to the station are demonstrated in Fig. 13a. Since these active modes are to access the train, the walk/bike flow is dependent on rail modal share. Hence these flows on active modes (walk or cycle to the station or to the CBD), as shown in Fig. 13a, follow a similar pattern to that of rail mode share and active-only mode share towards the CBD in Fig. 12a. The corresponding time per trip being active are as shown (in grey) in the background. Note that the peak journey time being active appears very close to the $\mathrm{CBD}$, where direct trips are made on bikes to the CBD, since cycling is the fastest mode of transport from these locations as explained earlier.

The CO uptake per person for their entire journey, for each starting location and for each mode, are demonstrated in Fig. 13b. Here for simplicity we assume that there is no difference between the $\mathrm{CO}$ concentration on different modes of transport. The change in background CO concentration (grey line), as shown in Fig. 13b, is a result of the increase of car flow, with this dependency clear from the cumulative car flow shown in Fig. 12a.

The differences in $\mathrm{CO}$ uptake per person are induced by the differences in breathing rates (on different modes), journey time and variations in $\mathrm{CO}$ concentration at different locations throughout their journey. As a result, as shown in Fig. 13b, the total $\mathrm{CO}$ uptake per person for rail users would be higher than that on car because of the higher breathing rate during access to the train station, i.e. when they cycle/walk. The CO uptake per person for rail (and active-only) users are therefore always higher than those on car. The peak CO uptake occurs near the CBD for those who cycle to work directly for three reasons: (1) the highest background $\mathrm{CO}$ concentration due to vehicle emissions under severe road congestion; (2) cyclists' breathing rate being up to three times of rest breathing rate; and (3) the maximum distance cycled is by those going direct to the CBD. 


\subsection{Policy Analysis}

For illustration purposes, here we compare the performance of combinations of two simple urban growth strategies and two road/rail capacity investment strategies:

1. Urban growth strategies

(a) Vertical growth. The length of the city is fixed. All demand will be evenly distributed within the city.

(b) Horizontal growth. The length of the city will increase with demand. All new demand will be distributed to the extended part of the city.

2. Transport investment strategies

(a) S1. Road capacity improvement only. Road capacity increases with population following scaling law. Rail capacity is fixed.

(b) S2. Investment on both road and rail capacity improvement. Both road capacity and train frequency increase with population following scaling law.

The following parameter settings are tested for illustration purposes in the following sections:

1. Urban growth strategies

(a) Vertical growth. Length of city fixed at $25 \mathrm{~km}(L=25 \mathrm{~km})$; with stations $5 \mathrm{~km}$ apart; initial demand $\left(Q_{0}=2000\right)$, i.e. initial population density $\left(Q_{0} / L=80 / \mathrm{km}\right)$.

(b) Horizontal growth. Length of city initialised at $4 \mathrm{~km}\left(L_{0}=4 \mathrm{~km}\right)$; population density is kept at an initial level of $500 / \mathrm{km}(Q / L=500 / \mathrm{km})$ while total demand increases from 2,000 to 30,000 , i.e. length of city increases from $4 \mathrm{~km}$ to $60 \mathrm{~km}$; with future stations $5 \mathrm{~km}$ apart.

2. Transport investment strategies

(a) S1. Road capacity improvement only. Road capacity initialised at $800 \mathrm{veh} / \mathrm{hr}$; increasing at a rate following scaling law, e.g. at a demand level of 15,000, the road capacity will be $4,260 \mathrm{veh} / \mathrm{hr}$. Rail frequency is fixed at 4 trains per hour.

(b) S2. Investment on both road and rail capacity improvement. Road capacity as above: initialised at $800 \mathrm{veh} / \mathrm{hr}$ and increasing at a rate following scaling law. Rail frequency initialised at 4 trains per hour; increasing at a rate following scaling law, e.g. at a demand level of 15,000, the road capacity will be $4,260 \mathrm{veh} / \mathrm{hr}$; the train frequency will be $21 \mathrm{trains} / \mathrm{hr}$.

\subsubsection{Trend Analysis}

As demand increases, we apply combinations of the strategies as stated above. The system performance in terms of three different performance measures: total travel time, percentage of population being active for longer than 10 minutes and total $\mathrm{CO}$ 
emissions are depicted in Fig. 14a and b. This shows the trend of system performance over time.

In terms of total travel time and total $\mathrm{CO}$ emissions, as demand increases, the performances deteriorate over time under all scenarios. This is obviously what we would expect with demand increase.

In terms of percentage of population being active for $\geq 10$ minutes, indicated in green in Fig. 14a and b, the picture is quite different. It is worth noting that for the chosen model parameters and scenarios, those active for more $\geq 10$ minutes are cycling for $\geq 1.67 \mathrm{~km}$, and hence are either located roughly midway between stations and taking the train, or cycling to the CBD. Under vertical growth the percentage being active increases over time, which can be explained by the fact that the rate of road capacity increase is not sufficient for the increase in population. As the overall level of road congestion is increasing, people increasingly choose rail and hence a higher percentage of people are active in accessing commuter stations as demand increases. Moreover, congestion near the CBD makes cycling attractive. The improved train service (in S2) attracts significantly more people cycling/walking to stations and hence an increase in rail modal share.

Under horizontal growth the picture is more complex. At lower population levels the city is "short" and hence does not have many rail stations. Cycling for $\geq 10$ minutes is dominated by people cycling directly to the CBD. As the city grows in population and physical extent, new stations are installed to maintain station separation of $5 \mathrm{~km}$ and this gives rise to the regular oscillations in Fig. 14b. As the city grows, so does the number of people cycling to stations in order to take the train to the CBD; cycling as an access mode starts to dominate those cycling for $\geq 10$ minutes. Comparing the two investment strategies, i.e. S2 versus S1, it is notable that congestion near the CBD is always worse in $\mathrm{S} 1$ and this encourages more people to cycle (rather than drive) directly to the CBD. This results in more people being active for $\geq 10$ minutes in $\mathrm{S} 1$ for lower populations when those cycling directly to the CBD dominates. For larger populations when the city is more spread out with more

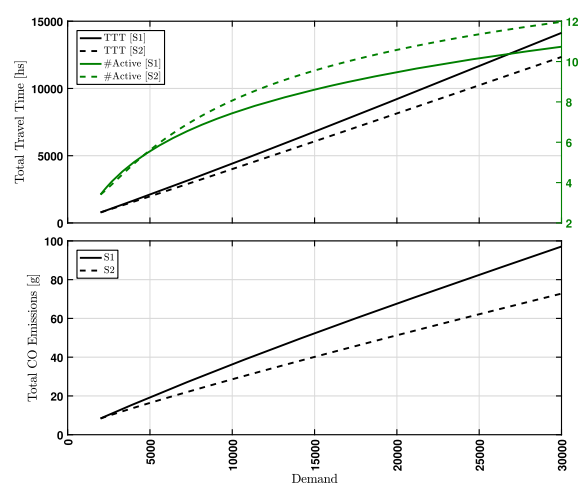

(a) Vertical growth

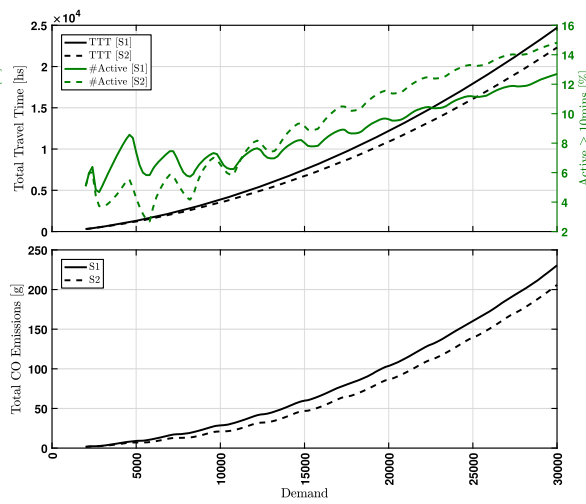

(b) Horizontal growth

Fig. 14 Performance trend analysis (stations are $5 \mathrm{~km}$ apart) 
stations, the increased train frequency in S2 attracts more people cycling/walking to stations and hence sees a higher proportion active for $\geq 10$ minutes than in $\mathrm{S} 1$.

\subsubsection{Spatial and Temporal Analysis}

Investment Strategy Comparison (S1 Versus S2) As explained earlier, the level of CO uptake of an individual traveller is dependent on his/her breathing rate (as determined by the mode of his/her own choice), journey time and variations in $\mathrm{CO}$ concentration at different locations throughout his/her journey. Therefore, it is important to understand the impact of the growth and investment strategies on the $\mathrm{CO}$ uptake at an individual level. In other words, to assess the health impact correctly, we should perform analysis spatially as well as temporally so that we can observe how the spatial performance of the system evolves over time as demand increases.

We start with looking at the spatial plot of mode share (in circles), aggregated time being active (in green bar) as illustrated in Fig. 15.

Note that here the linear city is on the y-axis with the CBD located at the bottom of the axis. The background grey scaled colouring represents the level of $\mathrm{CO}$ concentration at that location (darker indicates worse air quality). This graphic displays analysis at a 'block' level, where each 'block' represents the catchment area for a station; the catchment areas can easily be seen from the blue line in Fig. 12b. The location of the station is shown within each block as a blue triangle. Within each catchment block, the changes in air quality can also be observed.

Here we investigate the effect of different investment strategies (S1 and S2) under vertical urban growth strategy on modal share and time being active, as depicted in Fig. 16a and b, respectively. Within each catchment block, we observe the number of users, represented in circles (the size proportionate to the number of users), who

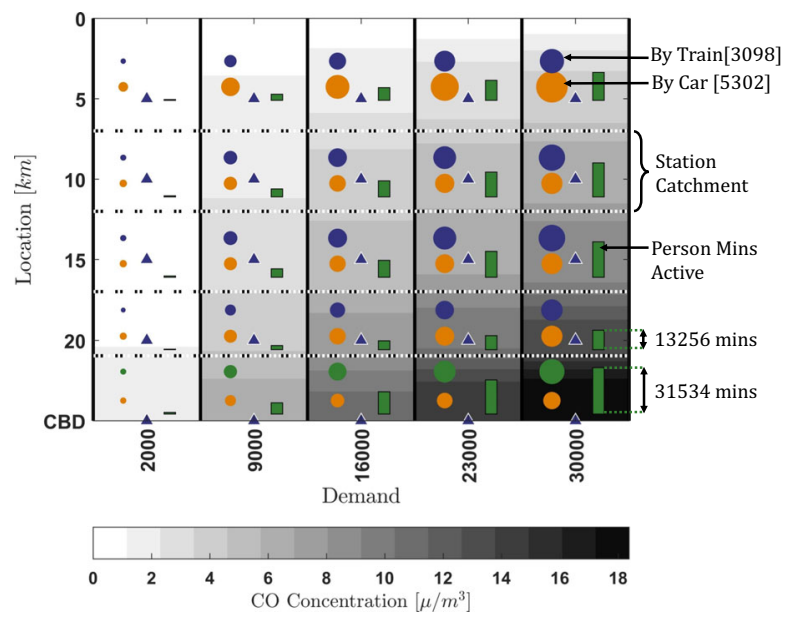

Fig. 15 An illustration of spatial plot of mode share \& aggregated time being active 
choose to drive (in orange) or take the train (in blue). By definition of the catchment areas, in the block closest to the CBD, users will choose to drive or cycle/walk directly to the CBD (shown in green). We also observe the total time being 'active' during access to a station or to the $\mathrm{CBD}$, represented by a green bar. The subsequent effect on total $\mathrm{CO}$ uptake by mode (for the whole population) and distribution of $\mathrm{CO}$ uptake per person for each mode under the two strategies are depicted in Fig. 17a and $b$.

With investment in road only, the air quality deteriorates significantly at a much faster rate as demand increases. When there is no increase in train service frequency to match population growth, more will choose to drive despite increased congestion. The congestion condition near the CBD increases, resulting in worse air quality as shown in Fig. 16a compared with Fig. 16b. Due to the relatively inconvenient train service, plus the highly congested road, a high proportion of those living near the CBD choose to cycle/walk to work directly despite the much higher $\mathrm{CO}$ concentration levels, resulting in a higher total time being active for the population but a much higher median $\mathrm{CO}$ uptake per person on the active-only group who bike to work directly. As depicted in the bar charts of total CO uptake by mode in Fig. 17a and $\mathrm{b}$, investment in rail in additional to road, will reduce the total $\mathrm{CO}$ uptake not only for active-only mode but also for car users. Most importantly, the median CO uptake per person will all decrease with investment in both road and rail, as shown in the boxplots in Fig. 17a and b.

From the analysis above, it is clear that investing in both road and rail, as compared to investing on road only, will increase modal share on rail along the city, which will not only help improve air quality but crucially will reduce $\mathrm{CO}$ concentrations near the CBD. This reduces the overall health impact induced by $\mathrm{CO}$ uptake during journey to work, particularly for those walking or cycling directly to the CBD.

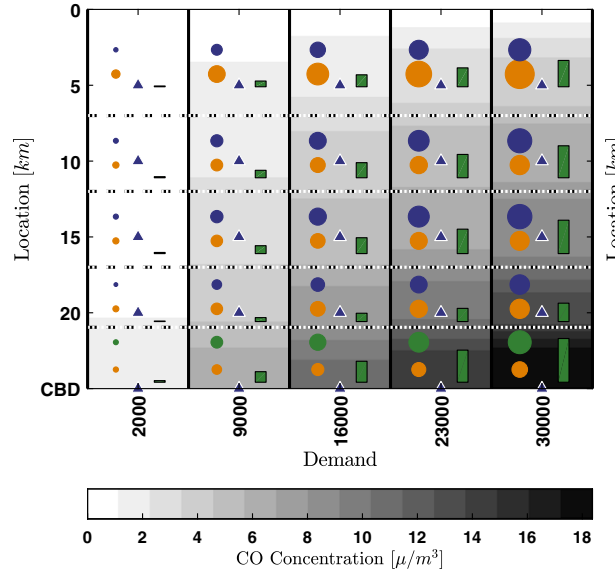

(a) S1. Road investment only

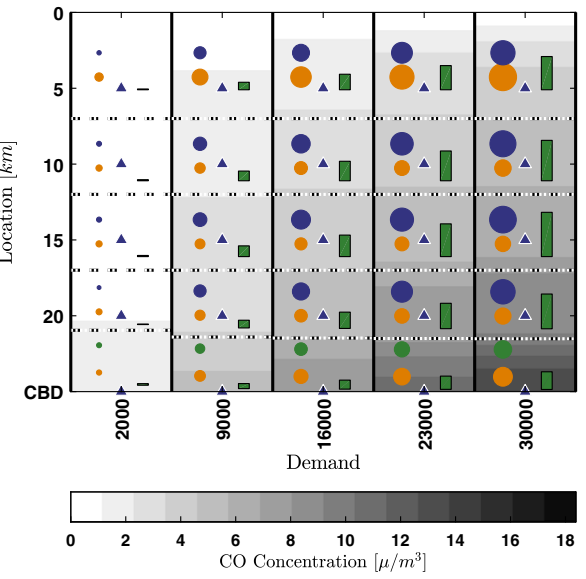

(b) S2. Both road \& rail investment

Fig. 16 Spatial plot of mode share and aggregated time being active by catchment area (vertical growth) 

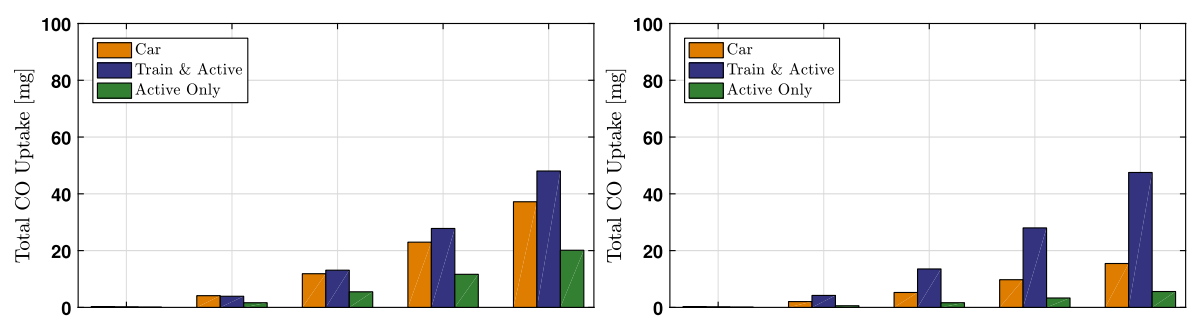

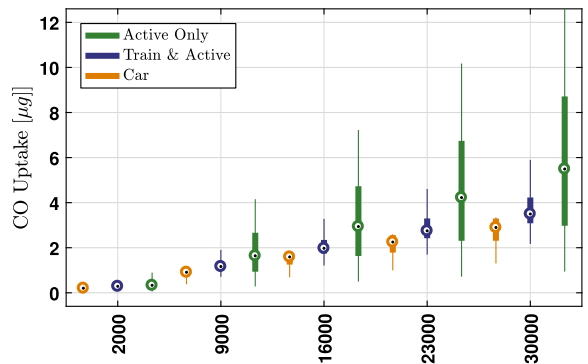

(a) S1. Road investment only

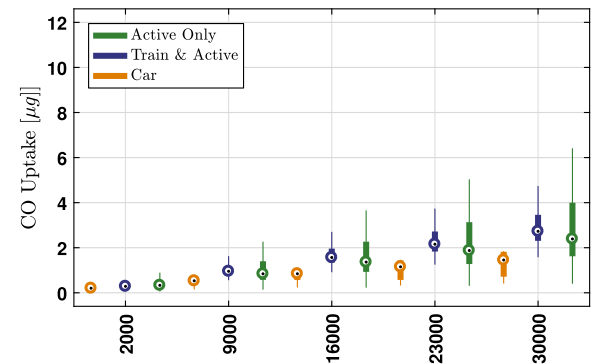

(b) S2. Both road \& rail investment

Fig. 17 Total CO uptake \& boxplot of CO uptake per person with increase in demand under vertical growth

Vertical Growth Versus Horizontal Growth In order to assess the impact of different growth strategies, we perform spatial and temporal analysis of mode share and aggregated time being active under vertical and horizontal growth strategies, as shown in Fig. 18a and b. The corresponding total CO uptake by mode and distributions of CO uptake per person on different modes are depicted in Fig. 19a and b.

Here we consider investment in road only (S1) for both growth strategies. Thus, the case of S1 \& vertical growth represents the worst case scenario and we investigate whether switching to a horizontal growth strategy might help improve the performances.

In terms of air quality, as shown in Fig. 18a as compared to Fig. 18b, the air quality near the CBD does improve. However, due to the longer distance travelled, as depicted in Fig. 19a and b, the total CO uptake on both car and rail, as well as the median uptake per person will increase. Users on car and rail will not benefit at all in terms of CO uptake. On the contrary, those cycle/walk to the CBD directly will experience lower concentration of $\mathrm{CO}$. As a result, the total $\mathrm{CO}$ uptake on active-only mode will be reduced.

Under horizontal growth strategy, residents might enjoy the same quality of life in terms of space, yet the level of CO uptake will increase as a result of the longer distance they will have to travel. This might induce worse health impact in the long term. 


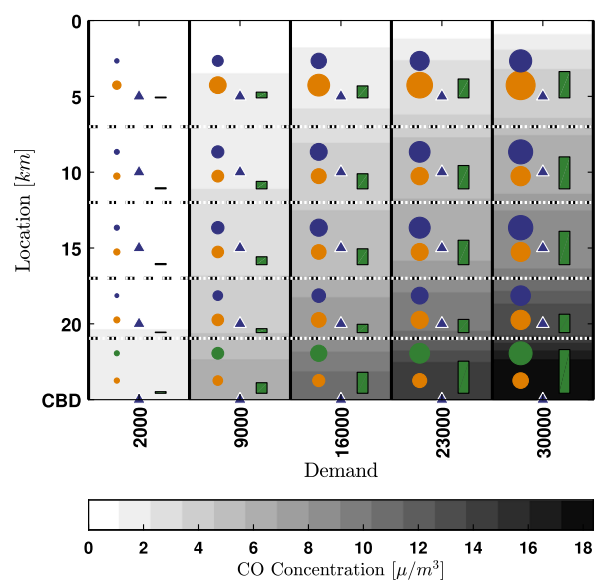

(a) S1 \& Vertical growth.

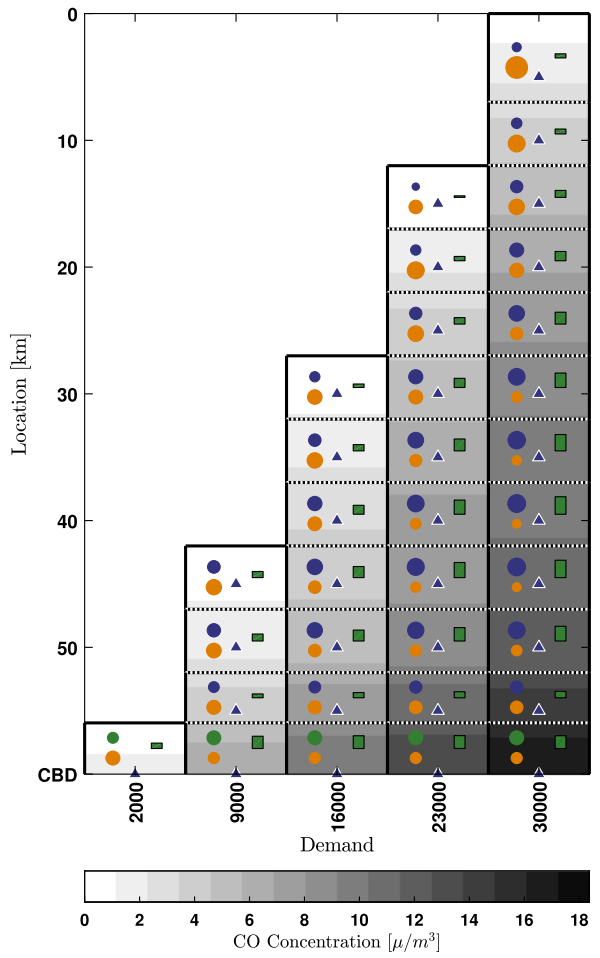

(b) S1 \& Horizontal growth.

Fig. 18 Spatial plot of mode share and aggregated time being active by catchment area
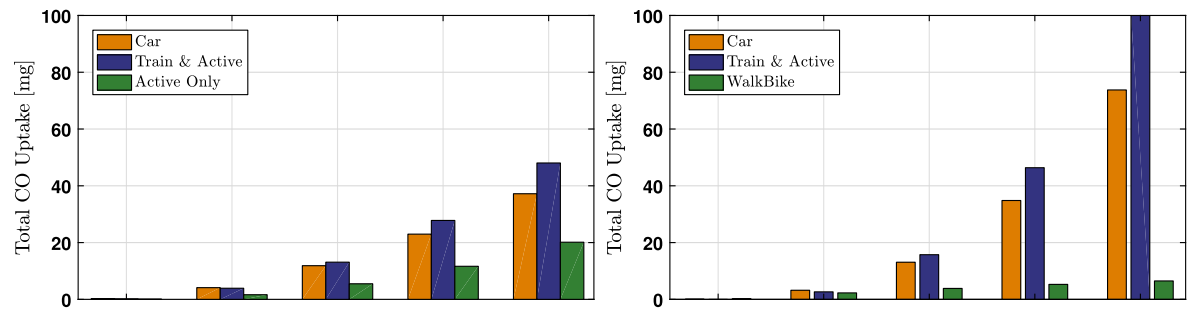

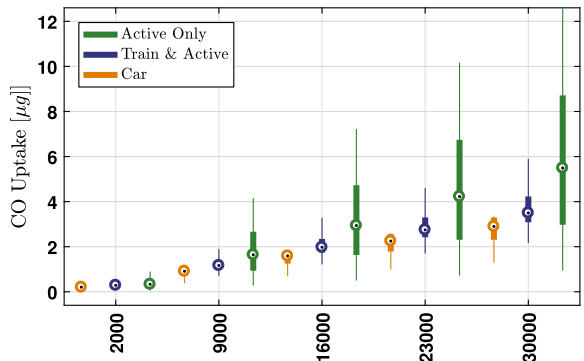

(a) S1 \& Vertical growth.

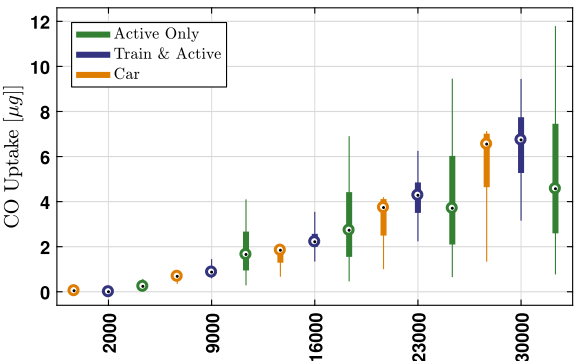

(b) S1 \& Horizontal growth.

Fig. 19 Total $\mathrm{CO}$ uptake \& boxplot of $\mathrm{CO}$ uptake per person with increase in demand 


\section{Conclusions and Outlook}

In this paper, we proposed a new multi-objective spatial analysis framework to evaluate the economic, environmental and health impacts of urban development and transport investment strategies in a linear monocentric city with continuum demand distribution, where residents have access to a road at any location or rail services by walking or cycling to the nearest station. The multi-objective modelling framework presented here allows the trade-offs between objectives to be examined at both the upper level, and from the perspective of travellers. The framework is flexible in that it allows component models to be altered or enhanced.

This modelling suite consists of two main subcomponents: (a) the urban growth and transport planning components; and (b) the air quality and health impact assessment component. The main purpose of the urban growth and transport planning components is to model travel behavioural response in terms of mode choice. We applied the concept of a three-objective user equilibrium model, wherein travellers maximise their time budget surplus (TBSmaxTUE). This incorporates the three most important factors influencing route/mode choice behaviour: travel time, travel time reliability and monetary cost. This new multi-objective bi-modal equilibrium model gives location-specific modal splits that depend on the travel time budget needed on each mode to achieve the desired level of reliability for each resident at that location.

With this method, we are able to capture the localised effect of accessibility to rail services on mode choice. The equilibrium analysis provides spatial information about the flows on every mode, including road, rail, walking and cycling, throughout the city. The air quality and health impact assessment component uses the flow and average speed information at each location along the road to determine local emissions concentrations. The impact of residents' mode choice on the environment in terms of overall air quality can therefore be determined. Most importantly, this model also captures the exposure of individual travellers to spatially heterogeneous pollutant levels, and hence the impact of individual mode choices on their own health in two aspects: (1) the level of physical exercise; and (2) the pollutant uptake during journey to work.

We demonstrate how the different components of the modelling suite can be applied to carry out system performance analysis with numerical examples. To evaluate system performance, we consider a set of four performance parameters: (1) total travel time; (2) total $\mathrm{CO}$ emissions; (3) median $\mathrm{CO}$ uptake during journey to work; and (4) percentage of population achieving a minimum of 10 minutes of exercise. We assess the performance for combinations of different strategies including urban growth strategies: vertical growth and horizontal growth; transport investment strategies: investment in road capacity improvement only and investment on both road and rail capacity improvements. By performing multi-objective analysis spatially and temporally, we demonstrate how this novel model can be applied to provide information for the trade-off between different criteria in policy decisions.

By introducing multi-objective bi-modal equilibrium model in a linear city, we have made a first step towards building a bi-level network design model with multiple objectives at both lower and upper levels. This approach has enabled the spatial and temporal analysis of economic, environmental and health impact assessment 
to be performed at both aggregate and disaggregate levels, represented by multiple objectives. Naturally there are several topics that can be considered for further development of this model. Residential location choices should be considered as a longer term decisions apart from day-to-day transport mode and route choice. Development of a bi-level optimisation model with multiple objectives at both the policy and user decisions' levels for a general multi-modal network would be our ultimate goal.

Open Access This article is distributed under the terms of the Creative Commons Attribution 4.0 International License (http://creativecommons.org/licenses/by/4.0/), which permits unrestricted use, distribution, and reproduction in any medium, provided you give appropriate credit to the original author(s) and the source, provide a link to the Creative Commons license, and indicate if changes were made.

\section{References}

Abdel-Aty MA, Kitamura R, Jovanis PP (1995) Investigating effect of travel time variability on route choice using repeated-measurement stated preference data. Transp Res Rec 1493:39-45

Affum J, Brown A, Chan Y (2003) Integrating air pollution modelling with scenario testing in road transport planning: The TRAEMS approach. Sci Total Environ 312(1-3):1-14

Alonso W (1960) A theory of the urban land market. Pap Reg Sci 6(1):149-157

Alonso W (1964) Location and land use. Harvard University Press, Cambridge

Anas A (1990) Taste heterogeneity and urban spatial structure: The logit model and monocentric theory reconciled. J Urban Econ 28(3):318-335

Bao J, Xu C, Liu P, Wang W (2017) Exploring bikesharing travel patterns and trip purposes using smart card data and online point of interests. Netw Spatial Econ 17(4):1231-1253

Ben-Ayed O, Boyce D, Blair III C (1988) A general bilevel linear programming formulation of the network design problem. Transp Res B Methodol 22(4):311-318

Bettencourt LMA, Lobo J, Helbing D, Kuhnert C, West GB (2007) Growth, innovation, scaling, and the pace of life in cities. In: Proceedings of the National Academy of Sciences, vol 104, pp 7301-7306

Boogaard H, Janssen N, Fischer P, Kos G, Weijers E, Cassee F, van der Zee S, de Hartog J, Meliefste K, Wang M, Brunekreef B, Hoek G (2012) Impact of low emission zones and local traffic policies on ambient air pollution concentrations. Sci Total Environ 435:132-140

Brons M, Rietveld P (2009) Improving the quality of the door-to-door rail journey: A customer-oriented approach. Built Environ 35(1):122-135

Chen Y-J, Li Z-C, Lam W (2017) Cordon toll pricing in a multi-modal linear monocentric city with stochastic auto travel time. Transportmetrica A: Transport Science, pages 1-28. Article in Press

De Lara M, de Palma A, Kilani M, Piperno S (2013) Congestion pricing and long term urban form: Application to Paris region. Reg Sci Urban Econ 43:282-295

de Nazelle A, Nieuwenhuijsen M, Anto J, Brauer M, Briggs D, Braun-Fahrlander C, Cavill N, Cooper A, Desqueyroux H, Fruin S, Hoek G, Panis L, Janssen N, Jerrett M, Joffe M, Andersen Z, van Kempen E, Kingham S, Kubesch N, Leyden K, Marshall J, Matamala J, Mellios G, Mendez M, Nassif H, Ogilvie D, Peiro R, Perez K, Rabl A, Ragettli M, Rodriguez D, Rojas D, Ruiz P, Sallis J, Terwoert J, Toussaint J-F, Tuomisto J, Zuurbier M, Lebret E (2011) Improving health through policies that promote active travel: A review of evidence to support integrated health impact assessment. Environ Int 37(4):766-777

de Nazelle A, Fruin S, Westerdahl D, Martinez D, Ripoll A, Kubesch N, Nieuwenhuijsen M (2012) A travel mode comparison of commuters' exposures to air pollutants in barcelona. Atmos Environ 59:151-159

Dirks KN, Johns MD, Hay JE, Sturman AP (2002) A simple semi-empirical model for predicting missing carbon monoxide concentrations. Atmos Environ 36(39-40):5953-5959

Dirks KN, Johns MD, Hay JE, Sturman AP (2003) A semi-empirical model for predicting the effect of changes in traffic flow patterns on carbon monoxide concentrations. Atmos Environ 37(19):27192724

Dirks KN, Sharma P, Salmond JA, Costello SB (2012) Personal exposure to air pollution for various modes of transport in Auckland, New Zealand. Open Atmos Sci J 6:84-92

Ehrgott M, Wang JYT, Watling DP (2015) On multi-objective stochastic user equilibrium. Transp Res B Methodol 81(3):704-717 
Energy \& Fuel Research Unit The University of Auckland (2008) Development of a vehicle emission prediction model (VEPM). Technical report, Auckland Regional Council

Engardt M, Johansson C, Gidhagen L (2011) Web services for incorporation of air quality and climate change in long-term urban planning for Europe. IFIP Advances in Information and Communication Technology 359 AICT:558-565

Fielbaum A, Jara-Diaz S, Gschwender A (2017) A parametric description of cities for the normative analysis of transport systems. Netw Spatial Econ 17(2):343-365

Fu X, Lam WHK, Chen BY (2014) A reliability-based traffic assignment model for multi-modal transport network under demand uncertainty. J Adv Transp 48(1):66-85

Götschi T, Garrard J, Giles-Corti B (2016) Cycling as a part of daily life: A review of health perspectives. Transp Rev 36(1):45-71

Hatzopoulou M, Miller E (2010) Linking an activity-based travel demand model with traffic emission and dispersion models: Transport's contribution to air pollution in Toronto. Transp Res Part D: Transp Environ 15(6):315-325

Huang J, Connors RD, Maher MJ (2014) Modeling network growth with scaling laws in a linear monocentric city. Transp Res Rec 2466:134-143

Jehiel P (1993) Equilibrium on a traffic corridor with several congested modes. Transp Sci 27(1):16-24

Kitthamkesorn S, Chen A, Xu X, Ryu S (2016) Modeling mode and route similarities in network equilibrium problem with go-green modes. Netw Spatial Econ 16(1):33-60

Lam T, Small K (2001) The value of time and reliability: Measurement from a value pricing experiment. Transport Res E-Log Trans Rev 37(2-3):231-251

Lee G, You S, Ritchie S, Saphores J-D, Sangkapichai M, Jayakrishnan R (2009) Environmental impacts of a major freight corridor. Transp Res Rec 2123:119-128

Li T, Wu J, Sun H, Gao Z (2016) Integrated co-evolution model of land use and traffic network design. Netw Spatial Econ 16(2):579-603

Li Z, Hensher DA, Rose JM (2010) Willingness to pay for travel time reliability in passenger transport: A review and some new empirical evidence. Transport Res E-Log Trans Rev 46(3):384-403

Li Z-C, Lam W, Wong S (2012a) Modeling intermodal equilibrium for bimodal transportation system design problems in a linear monocentric city. Transp Res B Methodol 46(1):30-49

Li Z-C, Lam W, Wong S, Choi K (2012b) Modeling the effects of integrated rail and property development on the design of rail line services in a linear monocentric city. Transp Res B Methodol 46(6):710-728

Li Z-C, Wang Y-D, Lam WHK, Sumalee A, Choi K (2014) Design of sustainable cordon toll pricing schemes in a monocentric city. Netw Spatial Econ 14(2):133-158

Lin J-J, Liao R-Y (2016) Sustainability SI: Bikeway network design model for recreational bicycling in scenic areas. Netw Spatial Econ 16(1):9-31

Lin X, Tampere CMJ, Viti F, Immers B (2016) The cost of environmental constraints in traffic networks: Assessing the loss of optimality. Netw Spatial Econ 16(1):349-369

Liu T-L, Huang H-J, Yang H, Zhang X (2009) Continuum modeling of park-and-ride services in a linear monocentric city with deterministic mode choice. Transp Res B Methodol 43(6):692-707

Liu W, Yang H, Yin Y (2014) Traffic rationing and pricing in a linear monocentric city. J Adv Transp 48(6):655-672

Lo HK, Luo XW, Siu BWY (2006) Degradable transport network: travel time budget of travellers with heterogeneous risk aversion. Transp Res B Methodol 40:792-806

Maheshwari P, Khaddar R, Kachroo P, Paz A (2016) Dynamic modeling of performance indices for planning of sustainable transportation systems. Netw Spatial Econ 16(1):371-393

Miandoabchi E, Farahani RZ, Dullaert W, Szeto WY (2012) Hybrid evolutionary metaheuristics for concurrent multi-objective design of urban road and public transit networks. Netw Spatial Econ 12(3):441-480

Mohan R (1979) Urban economic and planning models. John Hopkins University Press, Baltimore

Mueller N, Rojas-Rueda D, Cole-Hunter T, de Nazelle A, Dons E, Gerike R, Gotschi T, Int Panis L, Kahlmeier S, Nieuwenhuijsen M (2015) Health impact assessment of active transportation: A systematic review. Prev Med 76:103-114

Oja P, Titze S, Bauman A, de Geus B, Krenn P, Reger-Nash B, Kohlberger T (2011) Health benefits of cycling: A systematic review. Scand J Med Sci Sports 21(4):496-509

Rilett LR, Benedek CM (1994) Traffic assignment under environmental and equity objectives. Transp Res Rec 1443:92-99 
Schepers P, Fishman E, Beelen R, Heinen E, Wijnen W, Parkin J (2015) The mortality impact of bicycle paths and lanes related to physical activity, air pollution exposure and road safety. J Trans Health 2(4):460-473

Schindler M, Caruso G (2014) Urban compactness and the trade-off between air pollution emission and exposure: Lessons from a spatially explicit theoretical model. Comput Environ Urban Syst 45:13-23

Shekarrizfard M, Valois M-F, Goldberg M, Crouse D, Ross N, Parent M-E, Yasmin S, Hatzopoulou M (2015) Investigating the role of transportation models in epidemiologic studies of traffic related air pollution and health effects. Environ Res 140:282-291

Sider T, Alam A, Zukari M, Dugum H, Goldstein N, Eluru N, Hatzopoulou M (2013) Land-use and socioeconomics as determinants of traffic emissions and individual exposure to air pollution. $\mathrm{J}$ Transp Geogr 33:230-239

Smith B (1997) A review of monocentric urban density analysis. J Plan Lit 12(2):115-135

Stepniak M, Rosik P (2017) The role of transport and population components in change in accessibility: the influence of the distance decay parameter. Networks and Spatial Economics, pages 1-22. Article in Press

Szeto WY, Jiang Y, Wong KI, Solayappan M (2013) Reliability-based stochastic transit assignment with capacity constraints: Formulation and solution method. Transp Res Part C: Emerg Technol 35:286304

Szeto WY, Jiang Y, Wang DZW, Sumalee A (2015) A sustainable road network design problem with land use transportation interaction over time. Netw Spatial Econ 15(3):791-822

Taylor MAP, Susilawati (2012) Modelling travel time reliability with the burr distribution. In: Proceedings of EWGT2012 - 15th Meeting of the EURO Working Group on Transportation, September 2012, Paris, France

Wang DZW, Du B (2013) Reliability-based modeling of park-and-ride service on linear travel corridor. Transp Res Rec 2333:16-26

Wang JYT (2011) Appraisal of factors influencing public transport patronage. Technical report, New Zealand Transport Agency (NZTA) Research Report 434. http://www.nzta.govt.nz/resources/ research/reports/434/index.html

Wang JYT, Ehrgott M (2013) Modelling route choice behaviour in a tolled road network with a time surplus maximisation bi-objective user equilibrium model. Transp Res B Methodol 57:342-360

Wang JYT, Ehrgott M (2017) A three-objective user equilibrium model: Time surplus maximisation under uncertainty. Journal of Multi-Criteria Decision Analysis. Article in Press

Wang JYT, Yang H, Lindsey R (2004) Locating and pricing park-and-ride facilities in a linear monocentric city with deterministic mode choice case. Transp Res B 38(8):203-235

Wang JYT, Ehrgott M, Chen A (2014a) A bi-objective user equilibrium model of travel time reliability in a road network. Transp Res B Methodol 66:4-15

Wang JYT, Ehrgott M, Dirks KN, Gupta A (2014b) A bilevel multi-objective road pricing model for economic, environmental and health sustainability. In: The Seventeenth Meeting of the EURO Working Group on Transportation (EWGT2014), July 2014, Seville, Spain, volume 3 of Transportation Research Procedia, pages 393-402. Elsevier

Watling DP (2006) User equilibrium traffic network assignment with stochastic travel times and late arrival penalty. Eur J Oper Res 175(3):1539-1556

Wilson AG (1970) Entropy in urban and regional modelling. Pion, London

Woodcock J, Edwards P, Tonne C, Armstrong BG, Ashiru O, Banister D, Beevers S, Chalabi Z, Chowdhury Z, Cohen A, Franco OH, Haines A, Hickman R, Lindsay G, Mittal I, Mohan D, Tiwari G, Woodward A, Roberts I (2009) Public health benefits of strategies to reduce greenhouse-gas emissions: urban land transport. Lancet 374(9705):1930-1943

Woodcock J, Givoni M, Morgan A (2013) Health impact modelling of active travel visions for England and Wales using an integrated transport and health impact modelling tool (ITHIM). PLoS ONE 8(1):e51462

Yang L, Lam WHK (2006) Probit-type reliability-based transit network assignment. Transp Res Rec 1977:154-163

Yang X, Ban XJ, Ma R (2017) Mixed equilibria with common constraints on transportation networks. Netw Spatial Econ 17(2):547-579

You S, Lee G, Ritchie S, Saphores J, Sangkapichai M, Ayala R (2010) Air pollution impacts of shifting freight from truck to rail at California's San Pedro Bay Ports. Transp Res Rec 2162:25-34 